\title{
NAS Demand Predictions, Transportation Systems Analysis Model (TSAM) Compared with Other Forecasts
}

\author{
Jeff Viken* \\ NASA Langley Research Center, Hampton, VA, 23681 \\ Samuel Dollyhigh* and Jeremy Smith \\ Swales Aerospace, Langley Research Center, Hampton, VA 23681 \\ Antonio Trani ${ }^{\bullet}$, Hojong Baik ${ }^{\star}$, Nicholas Hinze ${ }^{\otimes}$, Senanu Ashiabor ${ }^{\star}$ \\ Virginia Polytechnic Institute and State University, Blacksburg,, VA, 24061
}

\begin{abstract}
The current work incorporates the Transportation Systems Analysis Model (TSAM) to predict the future demand for airline travel. TSAM is a multi-mode, national model that predicts the demand for all long distance travel at a county level based upon population and demographics. The model conducts a mode choice analysis to compute the demand for commercial airline travel based upon the traveler's purpose of the trip, value of time, cost and time of the trip,. The county demand for airline travel is then aggregated (or distributed) to the airport level, and the enplanement demand at commercial airports is modeled. With the growth in flight demand, and utilizing current airline flight schedules, the Fratar algorithm is used to develop future flight schedules in the NAS. The projected flights can then be flown through air transportation simulators to quantify the ability of the NAS to meet future demand. A major strength of the TSAM analysis is that scenario planning can be conducted to quantify capacity requirements at individual airports, based upon different future scenarios. Different demographic scenarios can be analyzed to model the demand sensitivity to them. Also, it is fairly well know, but not well modeled at the airport level, that the demand for travel is highly dependent on the cost of travel, or the fare yield of the airline industry. The FAA projects the fare yield (in constant year dollars) to keep decreasing into the future. The magnitude and/or direction of these projections can be suspect in light of the general lack of airline profits and the large rises in airline fuel cost. Also, changes in travel time and convenience have an influence on the demand for air travel, especially for business travel. Future planners cannot easily conduct sensitivity studies of future demand with the FAA TAF data, nor with the Boeing or Airbus projections. In TSAM many factors can be parameterized
\end{abstract}

\footnotetext{
* Senior Research Engineer, Systems Analysis Branch, NASA Langley Research Center, Hampton, Virginia, 23681.

* Senior Research Engineer, Swales Aerospace, NASA Langley Research Center, Hampton, VA, 23681, Associate AIAA Fellow

- Senior Engineer, Swales Aerospace, NASA Langley Research Center, Hampton, VA,

• Associate Professor, Department of Civil and Environmental Engineering, Patton Hall 200, Virginia Tech, Virginia, 24061, AIAA Senior Member.

^ Research Assistant Professor, Department of Civil and Environmental Engineering, Patton Hall 200, Virginia Tech, Virginia, 24061.

${ }^{\otimes}$ Research Associate, Department of Civil and Environmental Engineering, Patton Hall 200, Virginia Tech, Virginia, 24061.

\% Graduate Research Assistant, Department of Civil and Environmental Engineering, Patton Hall 200, Virginia Tech, Virginia, 24061.
} 
and various demand sensitivities can be predicted for future travel. These resulting demand scenarios can be incorporated into future flight schedules, therefore providing a quantifiable demand for flights in the NAS for a range of futures. In addition, new future airline business scenarios are investigated that illustrate when direct flights can replace connecting flights and larger aircraft can be substituted, only when justified by demand.

\section{Background / Problem Description}

The National Airspace System (NAS) currently does not have the capacity to meet today's demands, especially at the major hub airports when weather-constrained conditions occur. The demand for air travel continues to grow, and it is clear that capacity increasing concepts need to be developed to allow the traveling public to travel efficiently without major delays. For at least the last decade there have been forecasts that have predicted a severe future capacity shortfall, and have predicted NAS 'gridlock' within the next decade. Both the FAA and NASA have had ongoing programs to develop concepts to increase the capacity of the NAS. The capacity problems have reached a significant enough level that a multi-agency government planning group, the Joint Planning and Development Office (http://www.jpdo.aero) has been organized with its major goal being to develop a Next Generation Air Transportation System ${ }^{1}$ (NGATS) Fig. 1. For the JPDO and its parent agencies to be good stewards of the taxpayer's dollars, the projected future demands on the air transportation system need to be quantified as well as possible. Without quantifiably understanding the future demand to the system it will be hard to know if the designed capacity will meet the needs of the future demand. The system could be over-designed, exceeding capacity, leading to overspending, or under designed, not meeting capacity, leading to a system that will not meet the needs of the nation.

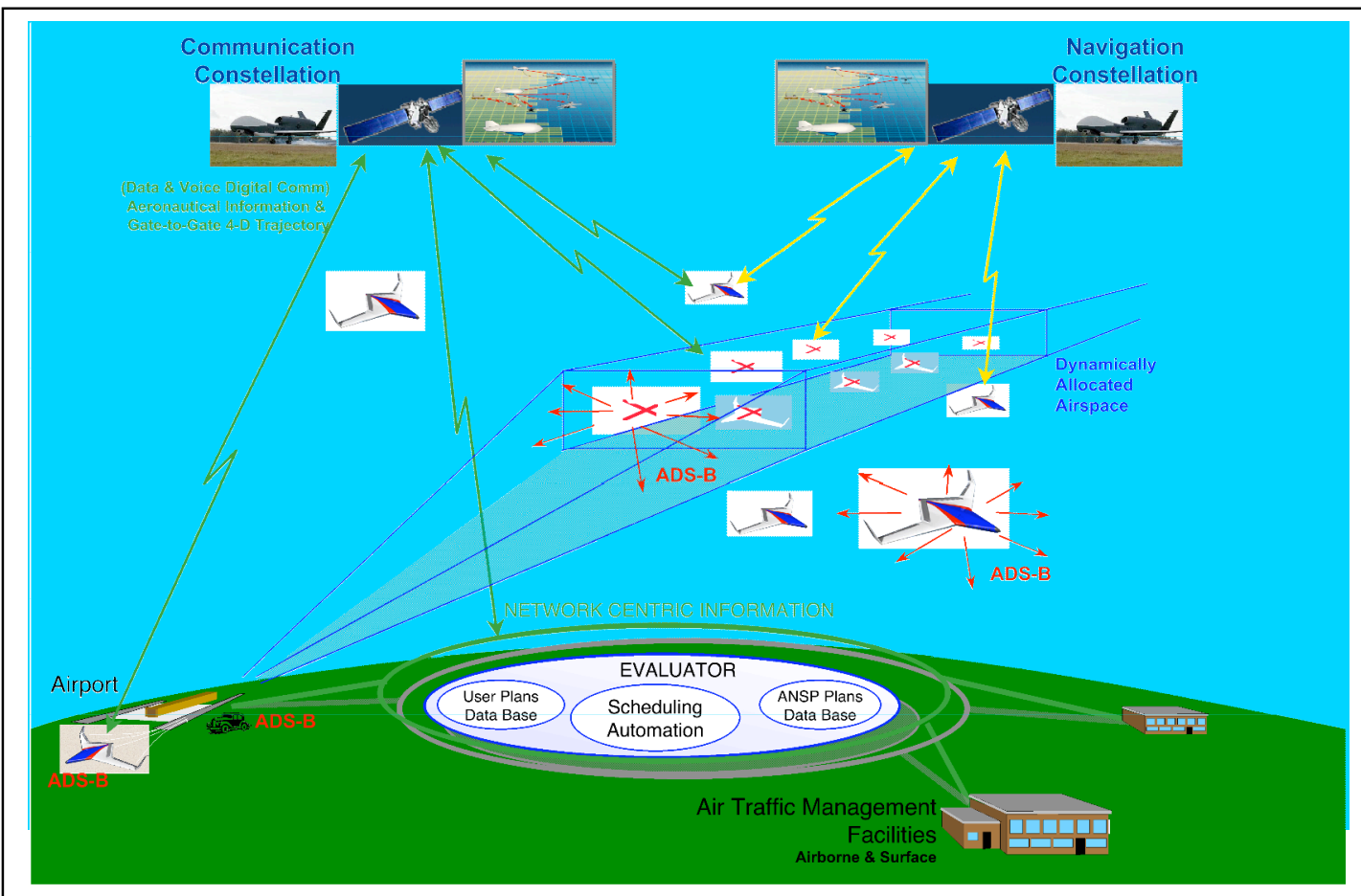

Figure 1. NGATS 2025 Airspace Schematic.

Most previous demand projections for the NAS have centered on the FAA's Terminal Area Forecast (TAF) predictions, or gross scale factors of the TAF predictions. The TAF has become the de facto official aviation demand forecast. Even with its strengths, the TAF has some limitations. First the TAF is developed from a series of individual airport models that uses trends in demographics to forecast changes in enplanements, it is not resolved at a national level. Second, the TAF is published yearly and is a result of a lengthy process within the FAA of analyzing the trends at the airports. Therefore, as a planning tool, it only gets updates to the current economic and demographic environment during its yearly developmental process. Third, the TAF is a static projection of a 
snapshot of the future that is the best projection of the FAA at the time of development. It is hard to use the TAF to conduct systems analysis studies for effects of rising fuel prices, increased delays or travel times, or even to explore alternate demographic futures. Lastly, since the TAF is a projection of trends of the existing airline network structure, it is hard to make demand predictions of future airline business scenarios, like the addition of a new hub, adding commercial service to new airports, or adding new technology aircraft to the fleet mix.

The current paper illustrates the basis of a framework, and tool, to predict future flight schedules for the National Airspace System based upon the projections of passenger demand for travel. The demand for commercial airline travel is predicted from a national model, the Transportation Systems Analysis Model. The demand for all long distance travel is computed at a county level as a function of income level and purpose (personal or business). Commercial airline travel is computed as a mode choice to automobile travel from doorstep-to-doorstep based upon trip cost, trip time and a traveler's value of time. The travel demand is aggregated (or distributed) from a county level to create airport demand. Therefore, TSAM reflects both county changes and represents the make up national travel trends. The TSAM model is a complete model that can be run within a 4 to 5 hour timeframe. Therefore various economic, demographic and system analysis studies can be conducted with the TSAM model to reflect sensitivities to various possible futures. Since the demand for travel is first computed at individual counties, new airports and/or hubs can be added to a future airline network and the resulting demand for travel can be computed.

A major strength of the TSAM analysis is that scenario planning can be conducted to quantify capacity requirements at individual airports, based upon different future scenarios. Different demographic scenarios can be analyzed to model the demand sensitivity to them. Also, it is fairly well known, but not well modeled, that the demand for travel is highly dependent on the cost of travel, or the fare yield of the airline industry. Except for a very few national disruptions, since the inception of commercial aviation the cost (or fare yield) of commercial airline travel has steadily decreased. This reduced cost of flying has significantly fueled the demand for commercial airline travel. The FAA projects the fare yield (in constant year dollars) to keep decreasing into the future. These projections can easily be disputed with the large rises in airline fuel costs. Future planners cannot conduct sensitivity studies of future demand with the TAF data, nor with the Boeing or Airbus projections. However, with TSAM these factors can be parameterized and various demand sensitivities can be predicted for the future. These resulting demand scenarios can be incorporated into future flight schedules, therefore providing a quantifiable demand for flights in the NAS for a range of futures.

The results from TSAM offer an alternative or complementary method to the FAA TAF forecasts to predict future demand for commercial airline travel. The real strength of the TSAM model is the ability to conduct sensitivity studies to possible demographic changes, cost model changes, or new commercial airline networks that can feed into systems studies.

\section{Introduction}

The daily traffic in the National Airspace System (NAS) is comprised of different categories of flights. There are scheduled commercial airlines, commuter flights and air-taxis that fly passengers for hire. There are military and freight flights also in the system. Also there are various categories of General Aviation flights. There are IFR (Instrument Flight Rules) and VFR (Visual Flight Rules) General Aviation flights that conduct both itinerant and local flights. Most studies concerning the NAS capacity consider the air traffic controller workload and runway capacity, which primarily handles aircraft flying IFR enroute and at the major FAA Operational Evolution Plan (OEP) airports. For its initial planning the JPDO has picked a "base/standard day' for NAS operations to conduct studies and make projections from. This base day is February 19, 2004. Table I has the numbers of the different categories of flights that occurred on that day.

The published goals of the JPDO state that NGATS will be designed in 2025 to handle three times the operations that NAS handled in 2004. However, do we know if this a needed goal? All of these categories of aircraft have different rates of traffic growth and should be accounted for accurately.

The current work discusses projections of the commercial airline and commuter traffic, which is nearly $2 / 3$ of the daily NAS traffic. The Aeronautics Systems Analysis Branch (ASAB) in the Systems Analysis and Concepts Directorate (SACD) is currently involved in developing models to project the General Aviation and freight traffic, which is another $25 \%$ of the daily traffic. Military traffic operations are driven more by the defense budget than economics and demographics of the population. The FAA openly states that they just project the current military operations as the future projections. The current study incorporates the Transportation Systems Analysis Model (TSAM) to predict the future demand for airline travel. TSAM is a multi-mode, national model that predicts the demand for all long distance travel at a county level (3,091 individual counties) based upon population and 


\begin{tabular}{|l|c|c|}
\hline \multicolumn{1}{|c|}{ Category } & $\begin{array}{c}\text { Number of } \\
\text { Flights }\end{array}$ & $\begin{array}{c}\text { Percentage } \\
\text { of Total }\end{array}$ \\
\hline Commercial & 24,514 & 45.3 \\
\hline $\begin{array}{l}\text { Commuter } \\
\text { \& Air-Taxi }\end{array}$ & 10,008 & 18.5 \\
\hline $\begin{array}{l}\text { General } \\
\text { Aviation }\end{array}$ & 12,123 & 22.4 \\
\hline Freight & 2,570 & 4.7 \\
\hline Military & 4,928 & 9.1 \\
\hline Total & 54,143 & 100.0 \\
\hline
\end{tabular}

Table 1. Daily Flight Totals in the National Airspace System (NAS).

can then be flown through air transportation simulators to quantify the ability of the NAS to meet future demand.

In addition, new future airline business scenarios are presented that illustrate flight demand requirements when direct flights can replace connecting flights, when justified by available demand. Studies have also been conducted to to determine the reduction in the number future flight operations, when larger aircraft can be added to routes, when justified by sufficient passenger demand.

It is important to note that we still have some limitation in developing commercial airline operations at airports in the NAS from the TSAM enplanement demand. TSAM can develop the origins and destinations of the trips relatively reliably. However there is a significant amount of traffic that transfers at the hub airports. On a national average about $36 \%$ of the travelers have a transfer which leads to an additional enplanement. Currently this is handled in projections by the following method. First, growth ratios of enplanement data at airports can be computed from the TSAM output. If it can be assumed that the transfer traffic grows at the same rate as originating and terminating traffic, then the growth ratios can be used to model the future traffic. An enhancement effort is underway to model the transfers of traffic at airports to allow TSAM to be able to project the actual enplanements at all airports in the future.

\section{Other Publicly Available Predictions}

\section{Federal Aviation Administration (FAA) Terminal Area Forecast (TAF)}

The Terminal Area Forecast (TAF) includes forecasts for active airports in the National Plan of Integrated Airport Systems (NPIAS). The FAA Statistics and Forecast Branch, Office of Aviation Policy and Plans, develops the TAF. The TAF summary ${ }^{1}$ model and TAF database ${ }^{3}$ can be accessed at http://www.apo.data.faa.gov/. The TAF database, which contains a query data application, allows access to historical (from1976) to forecast (current year to 2030) aviation activity data by individual airport, state, or FAA region. The Terminal Area Forecast contains historical and forecast data for enplanements, airport operations, and based aircraft. The data covers FAA towered airports ( 266) Federal contract tower airports ( 219), terminal radar approach control facilities ( $\sim 30)$, and nonFAA airports $(\sim 2,950)$. Data in the TAF are presented on a U.S. Government fiscal year schedule (October through September). Airport activity data in the TAF consist of the following:

Enplanements: the sum of originating and connecting passengers for air carriers and commuters.

Itinerant operations: for air carriers, commuters and air taxis, general aviation (GA), and military aircraft.

Local operations: for GA and military aircraft

Total instrument operations: for aircraft operations under radar control.

Based aircraft: for single engine, multi-engine, and jet GA aircraft

\section{Forecast Method}

Aviation activity forecasts for FAA-towered and Federal contract towered airports are developed using historical relationships between airport passenger demand and/or activity measures and local and national factors that influence aviation activity. Each estimate is examined for its reasonableness and consistency by comparisons with historical trends of airport activity. If forecasts deviate from their expected trend, the FAA uses other statistical 
techniques to reforecast the series. Other methods may include the use of regression analyses and the use of growth rates developed separately from the TAF. The TAF may incorporate estimates prepared by local authorities and/or recent FAA-approved airport master plan forecasts, when determined acceptable by the FAA staff.

The 35 airports in The FAA's Operational Evolution Plan (OEP) receive more in-depth review. These analyses include additional consideration for the effect of local economic variables (income and employment) and the growth of originating and connecting traffic, as well as airline cost. The hub forecasts also include assumptions about seating capacity and load factors for airport commercial aircraft. In addition, airport authority statistics are used to project baseline passenger levels, and the Official Airline Guide (OAG) is used to project near term departures and seats. The TAF assumes an unconstrained demand for aviation services based upon local and national economic conditions. An airport's forecast is developed independent of the ability of the airport and the air traffic control system to furnish capacity required to meet demand.

Because military operations forecasts have national security implications, the Department of the Defense (DOD) provides only limited information on future aviation activity. The TAF therefore projects military activity at its present level, except when there is a known specific change like a base closing.

For all FAA towered airports and non-FAA facilities with air carrier or commuter passenger service, the TAF corresponds to prevailing local and national trends. For non-FAA facilities, which rely solely on Form 5010 data for general aviation activity levels, operations levels are held constant unless otherwise specified by a local or regional FAA official.

Summary statistics presented in the TAF differ somewhat from the national totals in the FAA Aerospace Forecasts: Fiscal Years 2006-2030 (March 2006). There are three reasons for the differences. First, the TAF forecast methods rely, in part, upon the airport's historical national share of aviation activity, but also consider airport specific trends. Large hub forecasts are based, in part, on the projected local economic activity and airport specific airline fares. Second, the TAF includes facilities not serviced by the FAA in its totals. These facilities make up a large share of the general aviation operations activity shown in the summary tables. Finally, individual forecasts are not scaled to force aggregates to equal national totals.

The Airport Council International sponsors the annual FAA Commercial Aviation Forecast Conference every year. The FAA not only updates its TAF every year, it also improves the forecast's methods constantly. The TAF has become the de facto official aviation demand forecast. The FAA derives forecasted operations in the TAF for the small medium and large hubs in the following way:

- It forecasts the enplanements based on outputs of socioeconomic models, such as gross domestic product (GDP) and demographic growth rates, with consideration of originating traffic and connection traffic. Each major airport has its own specific models.

- It forecasts the load factors to and from each airport based on the demand, fare yield, and airlines cost.

- It forecasts the average number of seats per aircraft for arrivals and departures at the airport. It divides the forecasted enplanements by the forecasted load factor and by the forecasted average number of seats per aircraft to get forecasted operations.

In deriving the forecasts, flight delays due to traffic congestion are never explicitly considered. Implicitly, the TAF assumes that airport and ATC capacities will grow to meet the potential demand. The TAF provides projections of the following flight activity parameters by airport:

- Air Carrier enplanements

- Commuter enplanements

- Aircraft operations - includes Air carrier, commuter and General Aviation together

○ Local - begin and end at the same airport

- Itinerant - Flights from one airport to another airport

- Instrument operations - IFR operations that require controller supervision

○ Primary operations - Arrivals and departures at the primary airport

- Secondary operations - arrivals and departures at a secondary airport but require supervision by FAA at primary airport

○ Overflights - flights flying through airspace that require FAA supervision

\section{Boeing - Current Market Outlook}

Annually Boeing publishes its latest assessment of the 20-year demand for world travel. Their assessment estimates the jet airplane capacity needed to meet the projected growth in travel demand. The Boeing Current Market Outlook ${ }^{4}$ can be found at http://www.boeing.com/commercial/cmo/. The Boeing Current Market Outlook (CMO) is a projection of demand for air travel and the demand for fleets of jet aircraft and mixes of type of 
airplanes in the fleet. The demand for air travel is expressed in Revenue Passenger Kilometers (RPK), or the total number of revenue kilometers of demand that the airline industry would need to provide capacity for in the future. It is also broken down by international regions: North America, Latin America, Europe, Africa, Middle East, Northeast Asia, Southeast Asia, Southwest Asia, China, and Oceania. The results from the CMO can be provide information on a gross level about travel demand trends, but growth in North American RPK's can provide little information about the growth in travel demand or operations at specific airports in the continental United States. Therefore as a detailed projection at the airport level, the Boeing Current Market Outlook does not provide the kind detail necessary to conduct studies about airport demand and capacity.

\section{Airbus - Global Market Forecast}

The Airbus Global Market Forecast ${ }^{5}$ is Airbus' version of its 20 year projection for the demand for international air travel and the fleets of aircraft that will be needed to meet the future demand. The Global Market Forecast (GMF) can be found at http://www.airbus.org/. The GMF still only presents the demand for travel in Revenue Passenger Kilometers (RPK) and looks at the world in specific regions. The results from the GMF can be provide information on a gross level about travel demand trends, but growth in North American RPK's can provide little information about the growth in travel demand or operations at specific airports in the continental United States. Therefore as a detailed projection at the airport level, the Airbus Global Market Forecast does not provide the kind detail necessary to conduct studies about airport demand and capacity.

\section{The Transportation Systems Analysis Model (TSAM) Demand Generation}

\section{Overview}

The Transportation Systems Analysis Model (TSAM) predicts the number of trips of more than 100 miles between each of the more than 3000 counties in the continental United States. TSAM uses county-level socioeconomic data, dividing travelers into five household income groups and two travel purposes (business and non-business) to forecast the number of trips. The model uses proven transportation engineering methods to predict the number of travelers, selecting amongst three modes of travel: automobile, airline, and on-demand services using Very Light Jet aircraft (VLJ). The mode choice algorithm is based on travel time, travel cost, route choice convenience factors, and traveler demographics. TSAM draws on either large databases or external models for socioeconomic data; airline schedules, airline fares and travel times; auto travel times, routes and costs; VLJ travel times and costs; and airports characteristics.

In predicting air travel, TSAM considers other competing travel modes which travelers consider in making travel mode choices. As currently configured, TSAM can consider four choices (airline, auto, high-speed train, and another aeronautical technology). This sets TSAM apart from many of the other models used to predict air travel.

The model follows the traditional four-step transportation-planning framework:

- Prediction of the total number of trips (Trip Generation)

- Distribution of the trips generated amongst the origins and destinations (Trip Distribution)

- Prediction of the mode of travel individuals will choose for these trips (Mode Choice)

- Prediction of the route the travelers will choose for their trip (Network Analysis)

Figure 2 shows the framework of the model. The model employs several databases shown in the green cylinders in Figure 2. Databases include socioeconomic data (Census ${ }^{6}$, American Travel Survey ${ }^{7}$, and Woods and Poole CEDDS Economics ${ }^{8}$ ), airline schedules (Official Airline Guide ${ }^{9}$ ), fares (Department of Transportation Databank $1^{10}$ of ticket samples) and travel times, auto travel times and routes (MapPoint ${ }^{11}$ ), airports and their characteristics (FAA National Plan of Integrated Airport System - NPIAS ${ }^{12}$ and National Transportation Atlas Data NTAD ${ }^{13}$ databases), and aircraft technology (BADA ${ }^{14,15}$ data and format) and their corresponding travel time information.

While TSAM was developed to predict the number of travelers using small aircraft as part of the NASA Small Aircraft Transportation System (SATS) Program, the model can: 1) predict long-distance trips per county for all modes of transportation, 2) predict future air traffic volumes at airports, 3) forecast air travel between commercial airports, 4) forecast auto travel between counties, 5) quantify the impact of aviation technology and policy changes on traveler's mode choice, 6) estimate fuel consumption of various aviation policy alternatives, 7) predict travel times and costs for various modes of transportation.

Figure 3 illustrates graphically some of the information contained in the model. The model employs Geographic Information Systems Technology (GIS) developed by ESRI to display large numbers of input-output relationships on a computer screen. 


\section{Basic Transportation Modeling Process}

The purpose of travel is to conduct business, visit friends, attend a conference etc. This means that an intercity trip represents a mean to achieve a certain activity. This implies that in order to forecast trip demand, we should understand the relationships between activities and travel behavior. In transportation planning, we employ a traditional multi-step modeling process to study travel behaviors. The multi-step modeling process includes: 1) trip

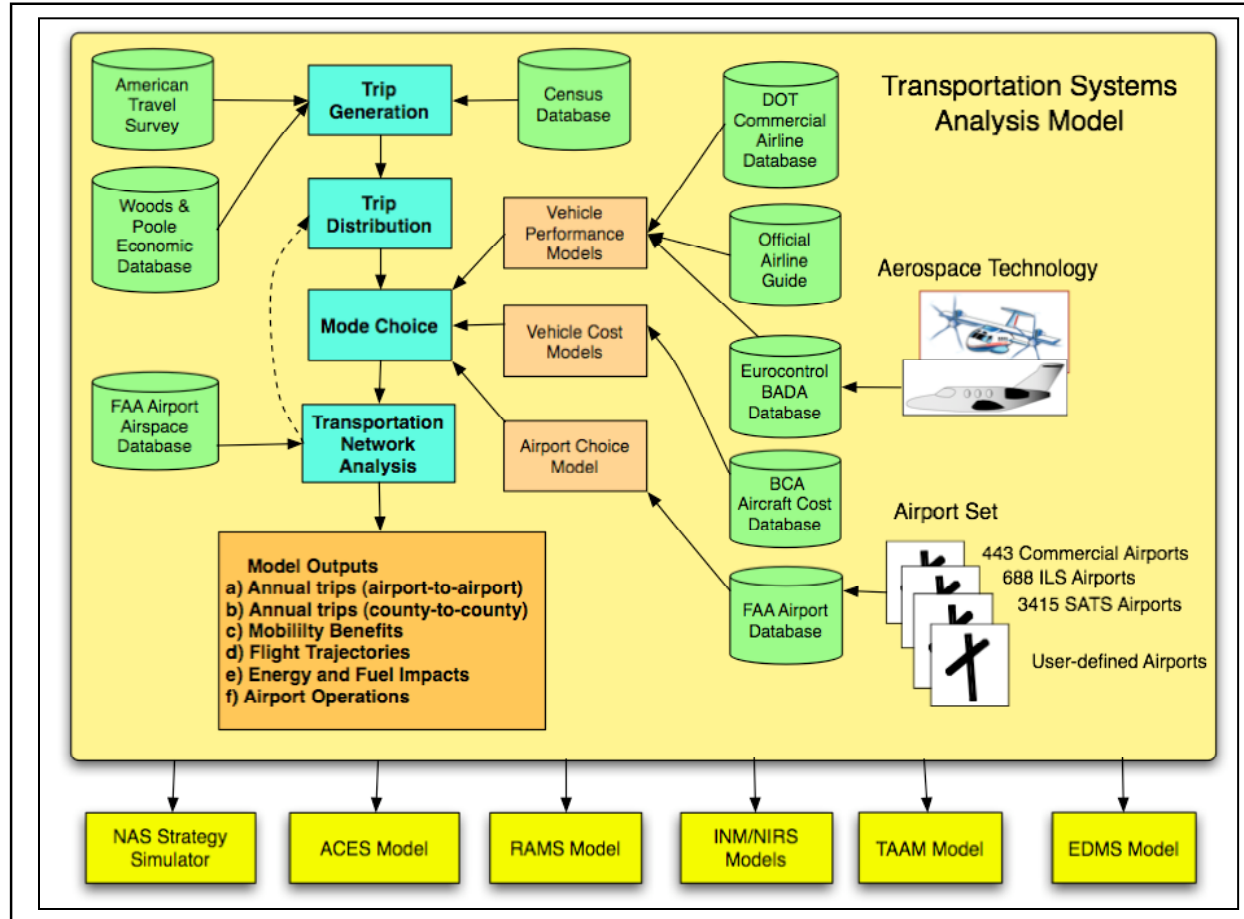

\section{Figure 2. TSAM Model Structure.}

generation, 2) trip distribution, 3) mode choice, and 4) trip assignment. A brief description of each process is presented in the following paragraphs.

- Trip generation: is used to predict the number of trips by trip purpose produced by each zone of activity and attracted to each zone. The output of this procedure is a simple Origin-Destination matrix with two vectors: one for productions and one for attractions.

- Trip distribution: A computation of the origin-destination (O-D) flows, that is, the trip ends predicted by the trip generation model are linked to form trip interchanges between zones. This results in a large trip interchange matrix (or sometimes called an origin-destination, O-D, table) showing the number of trips between an origin to a destination county. The units of the trip interchange matrix are person-trips per year between counties.

- Mode Choice: predicts the percentage of person-trips selecting each mode of transportation while traveling between two zones in the region of interest. A general aviation mode competes with automobile, commercial airline, bus, train, etc. In the mode choice model the trip interchange matrix obtained in the trip distribution step is decomposed into a number of trip interchange matrices consistent with the number of modes studied.

- Trip Assignment: places the O-D flows for each mode on specific routes of travel through the respective networks. In this step we are interested in studying the airport-airspace network interactions to assess the impact of passenger demand on the operations in NAS. Our goal is to convert airport-to-airport persontrip O-D table by aircraft type to an airport-to-airport aircraft O-D table using occupancy rate.

\section{Trip Generation Analysis}

Travel demand-related characteristics are usually socioeconomic variables applicable to each center of activity. Centers of economic activity in TSAM are defined at the county level and important socioeconomic variables are 
associated with these are employment, industrial capital, population, and gross regional and national product. Supply-related characteristics are intrinsic variables related to the transportation services offered. Examples of supply-related variables are: travel time, price of travel, frequency of travel, accessibility, dispatch reliability, etc.

The objective of a trip generation model is to forecast the number of person-trips that will originate from each region/zone $\left(O_{i}\right)$ and the number of person-trips attracted to each region/zone $\left(D_{i}\right)$ for a typical day of the target year.

In other words, the final results from the trip demand analysis are two column vectors with values $O_{i}$ and $D_{i}$ for

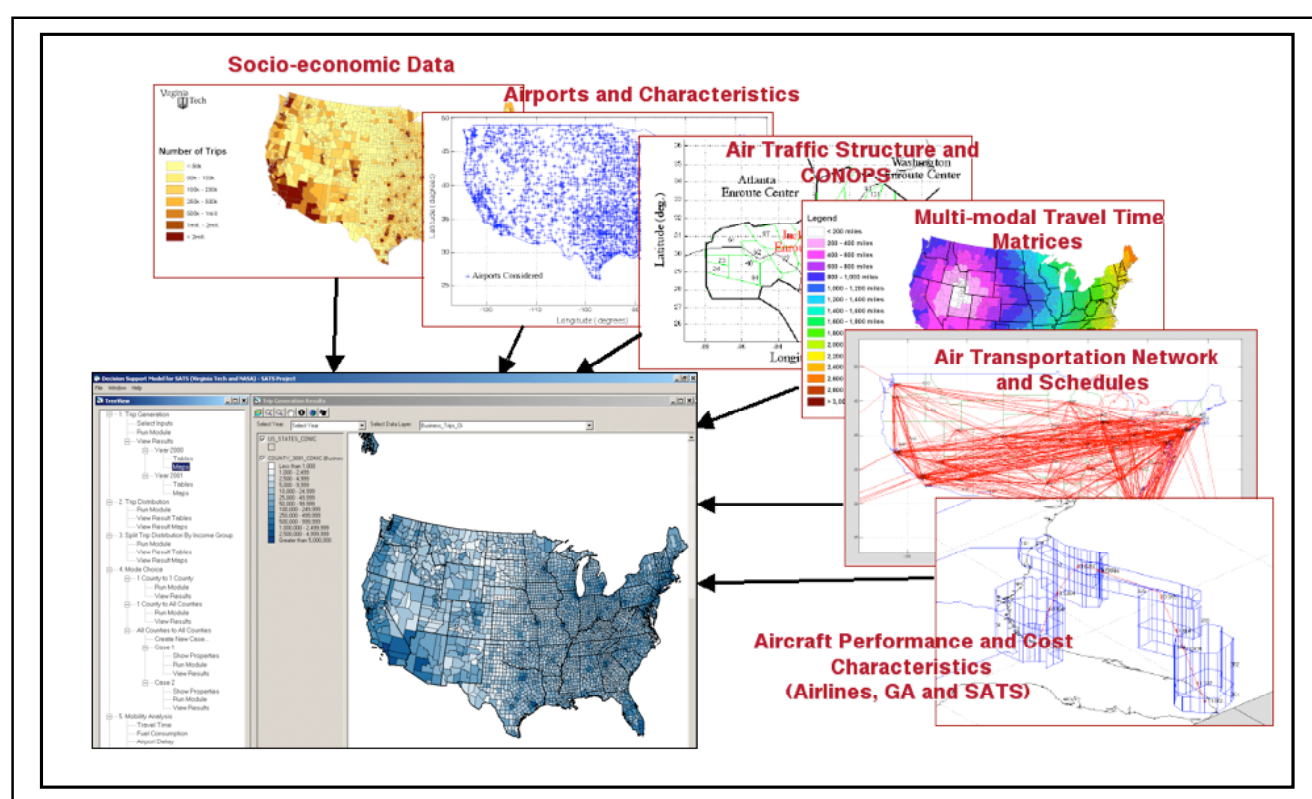

Figure 3. Typical Information Contained in the TSAM Model.

There are several data sources available to perform trip generation analyses. Three primary data sets used in our analysis are: (1) the American Travel Survey ${ }^{6}$ (ATS), (2) Census ${ }^{6}$ data, and (3) Woods and Poole ${ }^{8}$ forecasts of socioeconomic activity. These data sets are briefly described to help understand the complexities in the analysis.

\section{America Travel Survey ${ }^{7}$ (ATS)}

In 1995, the Bureau of the Census conducted the American Travel Survey (ATS) for the Bureau of Transportation Statistics (BTS). The ATS is still the most comprehensive survey of long distance trips in the United States since 1977. Trip and traveler information for all long-distance travel (defined as 100 miles or more one-way travel) was collected from approximately 80,000 U.S. households during a 12-month period in 1995. Each trip in the ATS was surveyed on more than 300 variables including trip purpose, modes of transportation, origin and destination, lodging type, and trip duration, demographic characteristics of travelers and their households.

Depending on the level of aggregation, two types of data sets exist in ATS: 1) Household trip data, and 2) person trip data. Both data sets are generated from the same data source, but summarized differently. For example, if a household consisting of three family members made a non-business trip by car, and all of the family members joined this trip, then the trip will create a single data record in the household trip data and there will be no description about how many people traveled together. On the other hand, three separate trips for each family member will be recorded in the person trip data.

It should also be noted that information on trip origin and destination in ATS is reported in an aggregate way using two types of regions: (1) Metropolitan Statistical Area (MSA) and (2) non-MSA areas. More precisely, ATS data identified a total of $161 \mathrm{MSA}$ areas and 50 non-MSA areas across the U.S. For instance, the state of Virginia consists of three MSAs (Richmond, Norfolk-Virginia Beach-Newport News, and Washington D.C.-MD-VA) and one large non-MSA area covering the rest of the state. 


\section{Census $^{6}$ data}

The U.S. Census Bureau has produced two types of data sets based on the ten-year census survey: (1) aggregate data, and (2) micro data. These data have been used to extract socioeconomic variables that constitute drivers that make people travel.

1) Aggregate Data: There are four summary files in the aggregate type of data. Summary Tape Files 1 and 2 contain "100-percent data" (collected from all households) at varying levels of geographical and racial/ethnic categories and include information on household relationship, sex, age, race, and housing tenure (owned or rented) and vacancy characteristics. Summary Tape Files 3 and 4 contain "sample data" (collected from approximately 1-in- 6 of the total population and housing units who completed the long form) at varying levels of geographical and racial/ethnic categories.

2) Micro Data: The micro data, also known as the Public Use Microdata Sample (PUMS) files, includes the actual responses to the Census questionnaires at 1-percent and 5-percent levels of those who completed the long form. In other words, PUMS contains the complete structure of each household, including the number of people in a given household, the household income, number of workers, etc. Constructed to protect respondent confidentiality, these files allow users to perform customized data analyses on a wide range of population and housing characteristics.

Among aggregate data, for the model we use the Summary Tape File 3A (STF-3A) data, which includes detailed information on the population (e.g., marital status, educational attainment, ancestry, disability, occupation, work status, and income) and housing characteristics (e.g., value of home, monthly rent, number of rooms, telephone service, vehicles available, and ancillary costs such as utilities, mortgages, taxes, and insurance).

\section{Woods and Poole ${ }^{8}$ Data:}

Complete Economic and Demographic Data Source (CEDDS) by Woods \& Poole Economics Inc. provides socioeconomic data projections through the year 2030, and come with an explanation of the projection methods, data definitions and data sources. The Woods \& Poole projections are based upon the latest Census data. The CEDDS includes population by age groups and households by income levels, as well as employment by industries. The products vary in the amount of data included, ranging from data for 50 states to data for 3091 counties in the U.S. All data are updated annually in year 1990-2006, and updated every five-year in 2010-2030. This data set can be used as an accepted source of future socioeconomic data projections and constitutes an exogenous driver for the TSAM model.

\section{Trip Distribution Analysis}

The purpose of this step is to derive a realistic Origin-Destination matrix (O-D) to achieve credible travel patterns between centers of transportation activity, counties in our case. The relevant question to be answered in this analysis can be expressed as follow:

Given $n$ trips generated by a center of activity $i$ (i.e., city or a region) and $m$ trips attracted to a center of activity $j$ find a feasible solution on how these trips distribute among centers of activity $i-j$ (or find volumes $v_{i j}$ for each origin-destination pair).

The rationale of trip distribution is as follows: all trip-attracting zones, $j$, in the region of interest are competing with each other to attract trips produced by each zone $i$. Everything else being equal, more trips will be attracted by zones that have a higher level of "attractiveness". The "attractiveness" is expressed as a function of salient socioeconomic factors of the zone and the relative proximity of the attraction zone to others. The most popular model for the trip distribution process is the Gravity Model, which is based on the Newton's law of gravitation. This model states that the force of the attraction between two zones is directly proportional to the product of the productions and attractions of the two zones and inversely proportional to the square of the distance between them. The model is expressed mathematically as follows:

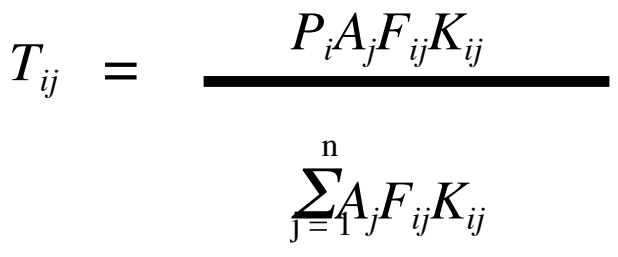

where, 
$P_{i}$ : trips produced by zone $i$,

$A_{j}$ : trips attracted by zone $j$,

$F_{i j}$ : friction factor (also called as travel distance/time factor) to be calibrated, and

$K_{i j}$ : zone-to-zone adjustment factor to be calibrated.

The first step for our Gravity Model is calibrating parameters ( $F_{i j}$ and $\left.K_{i j}\right)$ using "observed O-D tables" prepared using the ATS data set. This means it is necessary to acquire observed O-D tables before we conduct a calibration procedure. Besides the O-D table, a trip cost table providing travel cost between county pairs had been generated.

\section{Trip Attraction Analysis}

Unlike trip production analysis which is based on the household-based survey data, trip attraction models are usually developed using aggregated data such as zonal employments, population etc. Given trips attracted to each zone along with various types of socioeconomic data for those zones, a linear regression model was considered. A linear regression model is widely accepted by many of transportation planners, but is only valid as long as it is used to interpolate values of the explanatory variables. In TSAM a regression model would be built from state level data, however it would be used at the county level. In this case, the values of the independent variables at the county level are expected to be significantly smaller than that at the state level. This procedure could introduce large estimation errors, so it was decided not to use the regression model to estimate trip attractions. Instead unit trip attractions were computed by trip purpose and by state assuming that trip attraction rates vary from state-to-state. To decide the correct set of explanatory variable(s) from which to compute unit trip attractions, a correlation matrix was constructed to determine which variables correlated with business and non-business trip attractions. Fifteen variables were used for correlatio: (1) income per capita, (2) total employment, (3) total population, (4) farm employment, (5) agricultural services employment, (6) mining employment, (7) construction employment, (8) manufacturing employment, (9) transportation, communication, public utility employment, (10) wholesale trade

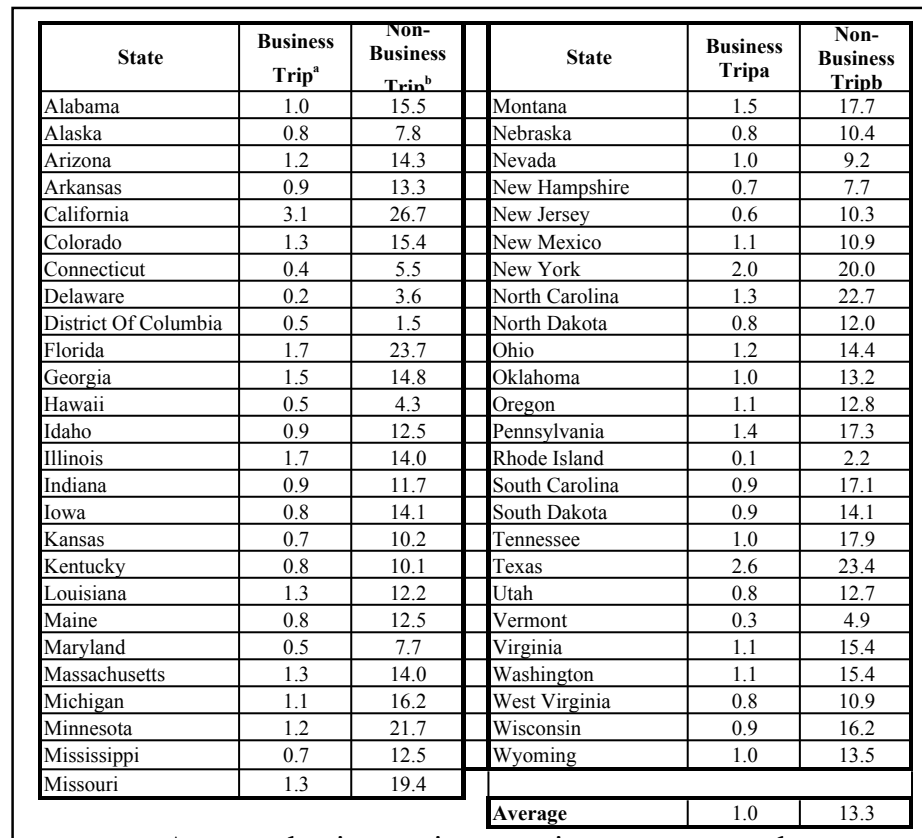

a. Average business trip attraction rate per employee.

b. - Average non-business rate per service employee. employment, 11) retail employment, 12) financial, insurance, and real estate employment, 13) service employment, 14) federal civilian government employment, and 15) federal military government employment. Results indicated that business and non-business trip attractions were quite well correlated with total employment (TE) and service employment (SE), respectively. Table 2 presents the results of the two trip rates per state: (1) business trip attraction per employee and (2) non-business trip attraction per service employee by state.

\section{Mode Split}

The intercity modal split analysis estimates the number of travelers taking specific modes of transportation while performing an intercity trip. The question to be answered in this analysis is:

\section{Table 2. Trip Attraction Rate by State.}

Given volumes of trips

$V_{i j}$ originating at a center of activity $i$

(i.e., city or a region) and ending at a center of activity $j$ find the most likely mode of transportation $k$ adopted by the traveler.

The deciding factors behind the choice of mode and path on intercity transportation networks are travel time, price of transportation on the paths, flight frequency, number of stopovers, perceived safety, mode accessibility, etc. Much of the past research in the development of modal split models centered on the use of Random Utility Models (RUM) developed from economic theory to study the "disutilities" associated with various modes of transportation. Logit and Probit mode choice models have been quite popular in transportation analyses to assess how users make 
decisions when comparing travel mode disutilities ${ }^{16,18}$. In addition to frequencies, different travel costs and travel times by different modes of transportation, mode travel choice depends on a variety of factors whose influence cannot be quantified without a survey of the travel population (sense of safety, sense of comfort, and others).

Passengers decide on a particular transportation mode according to the perceived travel times, perceived sense of safety and comfort as well as the approximately known rates, numbers of daily departures, and departure times. In this computation stage the interchange trip volumes between each origin destination pair is distributed between alternative modes being considered. Initially, stratified diversion curves were the predominant modeling tool. These are currently being replaced with probabilistic models that use utility and disutility functions. The most prevalent form of the logit models is the Multinomial Logit formulation. These Logit models aim at predicting the traveler's choice pattern. Factors that influence the traveler's choice can be grouped into three categories based upon,

- Trip type or purpose (work, or leisure trip)

- Trip Purpose (automobile is preferred to Public transport for social/shopping trips)

- Time of day

- Attributes of the mode (cost, level of service)

- Travel times (In-vehicle, waiting, access and egress times)

- Monetary cost (fare, direct operation costs)

- Comfort, convenience, safety etc.

- Characteristics of the traveler (income, car ownership)

- Level of income

- Vehicle availability

- Vehicle operating license

Modal split models may either be aggregate or disaggregate. When mode split is implemented before distribution (i.e. directly after trip generation) the model is referred to as a trip-end model, and the output is trips split by mode. This approach gained ground in the continental US as it allowed individual characteristics (which are considered a significant factor in the travelers' mode selection process) to be captured in the mode split analysis. By implementing the model in this order, the socioeconomic characteristics of the individual can be captured directly in the mode choice process. However as trip distribution has not taken place, there is no indication as to the destination of trips and this makes the model insensitive to policy decisions. It appears that there is nothing the decision maker can do to influence the choice of mode. For example, in such a model improving public transport, restricting parking and charging for use of roads has no effect on how travelers select their modes as their decisions are based only on their characteristics ${ }^{19}$. A nested logit model was developed to split the output of the trip distribution results (inter-county person-trips) into inter-county person-trips by mode of transport. The model splits the trips by computing the market share (\%) of competing modes for each origin-destination pair. The mode split analysis is executed considering the aircraft travel characteristics of every mode and characteristics trip maker. Each mode of transportation has a unique travel time and travel cost (supply side variables). Similarly, the trip maker has unique socioeconomic income characteristics (demand side variables). The transportation modes considered in the model are automobile, commercial aviation, high speed train, and, other defined modes, such as Small Aircraft Transportation Systems (SATS). Trip makers (travelers) are split into five income groups based on annual household income.

The coefficients of the model were estimated using a two-stage process. First a standard logit model was hypothesized, and then transformed it into a nested logit model. This approach was necessary because the model coefficient calibration was done from a synthetically generated dataset. The only comprehensive nation-wide database with information on trip makers and mode selection behavior is the American Travel Survey ${ }^{7}$ (ATS). The ATS database has information on the mode travelers used, the stage length of trips and household income of the travelers. However, the ATS data available to the public does not have detailed information pertaining to the origin and destination of trips. Using the ATS alone, we have no means of identifying what alternative modes the traveler considered when making his decision (for example: was the traveler selecting between auto and a set of airport routes?). Without this information directly, we cannot estimate the coefficients of a nested logit model. To overcome this hurdle, travel time and costs were inferred for every trip in the ATS data set. Using the coefficients, dissimilarity value parameters were generated for a nested logit model. The logit model estimated using the ATS data is written mathematically as, 


$$
P_{i j}^{k l}=\frac{e^{U_{i j}^{k l}}}{\sum^{e^{U_{i j}^{k l}}}} \quad \text { where }\left(\boldsymbol{\Sigma} P_{i j}^{k l}=1\right)
$$

where:

$\mathrm{U}_{\mathrm{ij}}^{\mathrm{kl}}$ : is the utility value associated with a trip maker of income group $l$ making a trip from origin county $i$ to destination county $j$ using mode $k$.

$\mathrm{P}_{\mathrm{ij}}{ }^{\mathrm{kl}}$ : is the probability of a trip maker of income group $l$ choosing a transportation mode $k$ when making a trip between origin county $i$ and destination county $j$.

One form of the equation for the utility expression employed in our analysis is,

$$
U_{i j}^{k l}=\alpha_{1} \times \text { Travel Time }_{i j}^{k} \times \operatorname{VOT}^{l}+\frac{\boldsymbol{\alpha}_{2} \times \text { Travel Cost }_{i j}^{k}}{\text { Household Income }}
$$

where:

$\alpha_{1}$ and $\alpha_{2}$ are the model coefficients that need to be calibrated,

$V O T^{l}$ is the value of time of the traveler from income group $l$,

Travel Time $e_{i j}^{k}$ is the travel time between origin county $i$ and destination county $j$ using mode $k$, Travel Cost ${ }_{i j}^{k}$ is the travel cost between origin county $i$ and destination county $j$ using mode $k$,

Household Income $e^{l}$ is the household income of a trip maker of income group $l$.

The simple logit model described above suffers from an undesirable property due to an assumption in the model that there is independence of the utilities across choices, a property referred in the literature as Independence from Irrelevant Alternatives (IIA). The nested logit model overcomes this assumption by assuming decisions are taken

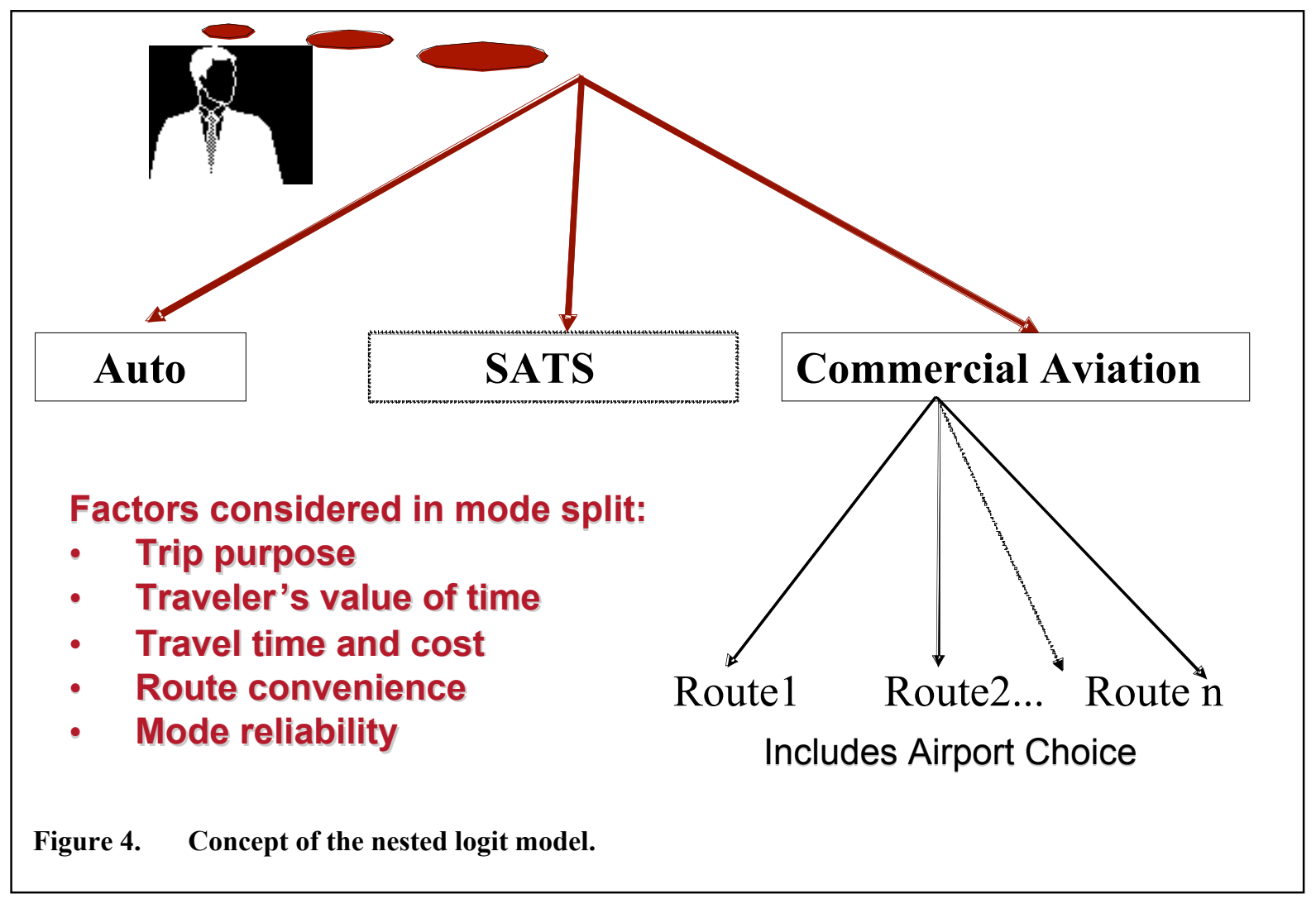


sequentially following a decision tree, thereby restricting the independence assumption only at nodes above the nest. A nested logit structure is shown in figure 4. Each route is considered as an alternative due to differences in cost and travel time values. The mathematical form of the nested logit is more elaborate then the simple logit model. In addition to the coefficients, dissimilarity parameters need to be estimated for each mode. Let $\mathrm{m}$ represent the two levels in figure 4 above. Let the level with the routes be level 1 and that with the modes be level 2 . Assuming that there is a dissimilarity parameter $\theta_{\mathrm{k}}$ for each mode, an inclusive value is defined as:

$$
\operatorname{Inc}_{\boldsymbol{k}}=\log \left(\boldsymbol{\Sigma}_{m} \exp \left(\boldsymbol{U}_{(i j, m)}^{k l}\right)\right) \text { for } m=1
$$

$$
P_{(i j, m)}^{k l}=\frac{\exp \left(\operatorname{Inc_{k,m}} \times \boldsymbol{\theta}_{k}\right)}{\sum_{\boldsymbol{k}} \exp \left(\operatorname{Inc}_{k, m} \times \boldsymbol{\theta}_{k}\right)} \text { for } m=2
$$

$\mathrm{P}_{(\mathrm{ij}, \mathrm{m})}^{\mathrm{kl}}$ is the probability of a trip maker of income group $l$ using a transportation mode $k$ in the higher nest $m=2$ when making a trip between origin county $i$ and destination county $j$.

If we specify each of the modes independently then the probability for each mode at the rout level is:

$$
\begin{aligned}
& p_{\text {auto }}=\frac{e^{s p_{\text {auto }} \cdot \log \left(\exp \left(u_{\text {auto }}\right)\right)}}{e^{s p_{\text {auto }} \cdot \log \left(\exp \left(u_{\text {auto }}\right)\right)}+e^{s p_{\text {air }} \cdot \log \left(\exp \left(\sum_{k=1}^{\text {all }} \sum_{\text {route }}^{\text {a route_k }}\right)\right)}+e^{s p_{\text {SATS }} \cdot \log \left(\exp \left(u_{S A T S}\right)\right)}}, \\
& e^{s p_{\text {air }} \cdot \log \left(\exp \left(\sum_{k=1}^{\text {all_ }}{ }^{\text {route }} u_{\text {air_route_k }}\right)\right)}
\end{aligned}
$$

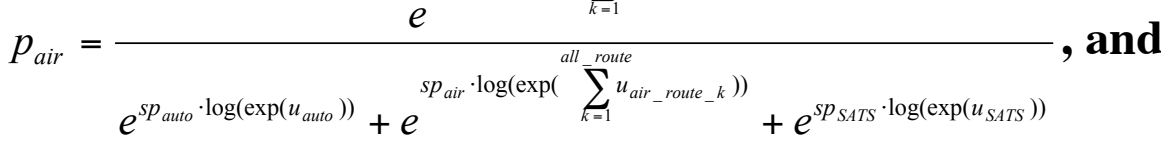

$$
\begin{aligned}
& p_{\text {sats }}=\frac{e^{s p_{\text {SATS }} \cdot \log \left(\exp \left(u_{\text {SATS }}\right)\right)}}{e^{s p_{\text {auto }} \cdot \log \left(\exp \left(u_{\text {auto }}\right)\right)}+e^{s p_{\text {air }} \cdot \log \left(\exp \left(\sum_{k=1}^{\text {all } r \text { route }} u_{\text {air_route } k}\right)\right)}+e^{s p_{\text {SATS }} \cdot \log \left(\exp \left(u_{\text {SATS }}\right)\right)}} \text {. }
\end{aligned}
$$

Within the commercial airline, nest the probabilities for each air route are:

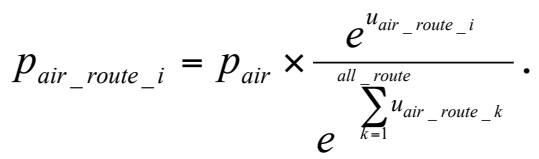

where,

$s p_{\text {auto }}, s p_{\text {air }}, s p_{S A T S}$ : scale parameter (inclusive value) for auto, air and SATS respectively.

$\mathrm{u}_{\text {auto }}, \mathrm{u}_{\text {air }}, \mathrm{u}_{\mathrm{SATS}}$ : utility value for auto, air and SATS respectively.

The nested logit (dis)utility function is 


$$
\begin{aligned}
& U_{i j}^{k l}=\alpha_{0} \text { Travel Time }{ }_{i j}^{k}+\alpha_{1} \text { Travel Cost } t_{i j}^{k 1}+\alpha_{2} \text { Travel Cost } t_{i j}^{k 2} \\
& +\alpha_{3} \text { Travel Cost }{ }_{i j}^{k 3}+\alpha_{4} \text { Travel Cost } t_{i j}^{k 4}+\alpha_{5} \text { Travel Cost } t_{i j}^{k 5}
\end{aligned}
$$

Where, $U_{i j}^{k l}$ : The utility for mode $k$ ( $k=$ Automobile, Commercial Airline etc) traveling from origin county $i$ to destination county $j$ by a traveler in income group $l$.

\section{Model Outputs}

The model output is a set of inter-county person-trip tables by mode, that are further split between the five income groups. For the scenario with only automobile or commercial airline (without SATS) the following tables are generated:

- County-to-county person-trips by commercial aviation by income group (3,091 by 3,091 by 5$)$

- County-to-county person-trips by automobile by income group (3,091 by 3,091 by 5 )

- An airport-to-airport person-trip table by income group (443 by 443 )

For the SATS case there are additional tables:

- County-to-county person-trips using SATS by income group (3,091 by 3091 by 5 )

- An airport-to-airport person-trips using SATS by income group (3,416 by 3,416 by 5$)$

The outputs of the model are illustrated graphically in Figure 5. Figure 5 shows the sequence to estimate intercounty trips by mode. The figure shows graphically that four 3,091 by 3,091 inter-county matrices, representing four income levels and output of the trip distribution method, are modified by the mode choice model and split into

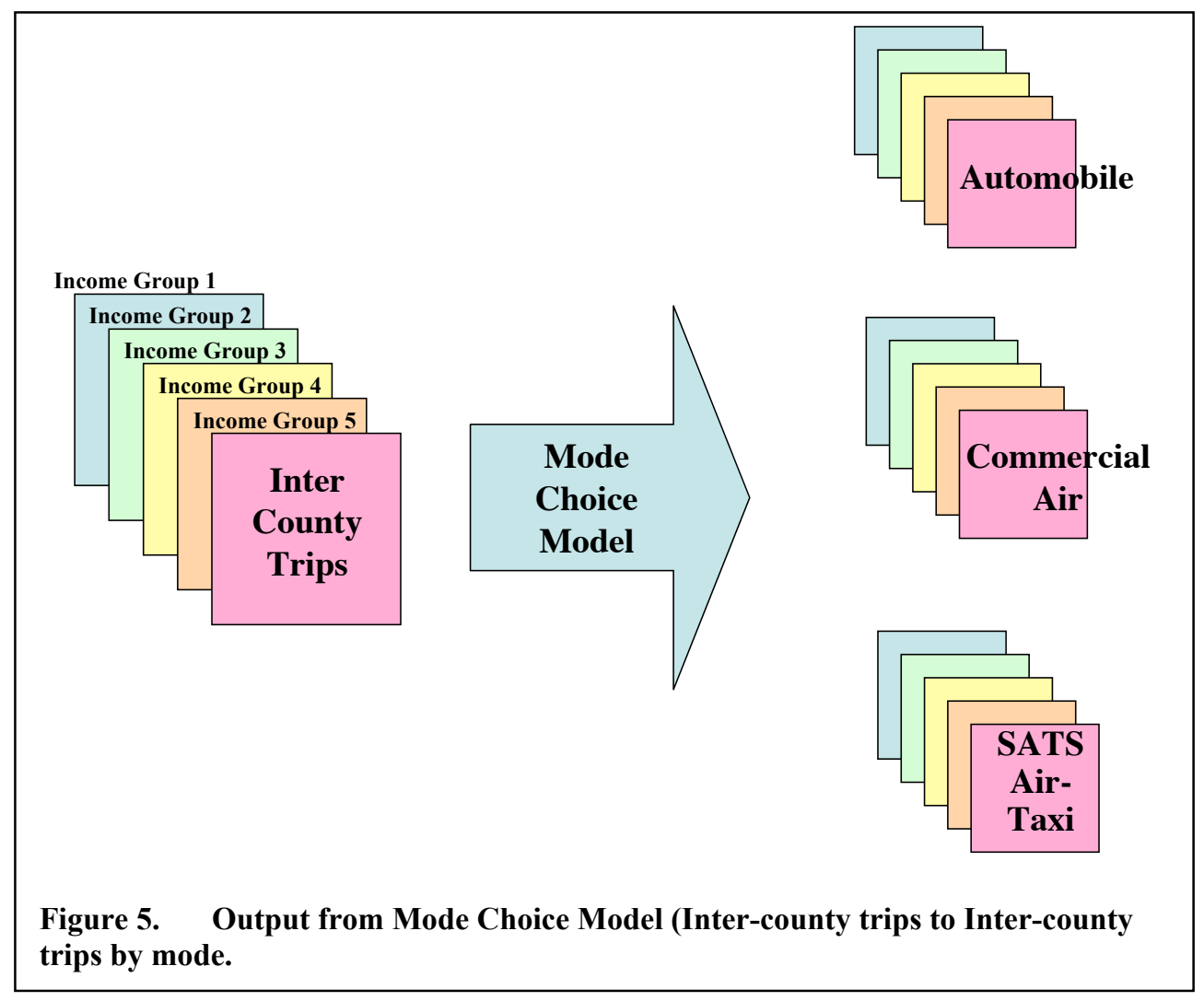

representing airport-to-airport activity. four three sets of four matrices representing intercounty trips by mode. The model then splits the inter-county trips and split them into the SATS set of airports $(3,416$ by 3,416 matrices) for five income levels. The processes illustrated graphically in Figure 5 demonstrate the size of the output of the transportation systems model. Overall, the mode choice produces fifteen tables of size 3,091 by 3,091 (see Figure 5) and eight 3,416 by 3,416 tables 


\section{Overview - TSAM Airport Choice Model}

The airport choice model is 'origin county' specific and two sets of candidate airports are developed for each county. The maximum number of candidate airports for each county airport set is limited to three airports. The current assumption is that users rarely consider more than three commercial service airports when planning trips. Two airport sets are required to model the dissimilar behavior of travelers when taking intercity trips. For example, it is known that most travelers are willing to travel longer inter-modal distances to access airports with cheaper fares when making long trips. Hence a separate airport set was developed for short and long trips. Though it is difficult to assess with precision what stage length qualifies as a long trip, it is currently assumed that any great circle distance of more than 300 miles between county centroids is a "long trip". Business travelers tend to place a higher premium on time relative to cost and thus they will use the closest airport even if the fares are high. The airport selection rule for short trips can be summarized a follows:

- Select all airports in a 100 mile radius from the centroid of the county (great circle distance)

- Select the closest airport as the first candidate airport

- Select the two airports with the cheapest fares as the second and third candidate airports

- If there is no airport within 100 miles increase radius until one airport is found.

For long trips the closest airport is retained, however a search radius of two hundred miles is used. The rules are similar to those for the short trip except that enplanements are used in place of average fares.

- Select all airports within 200 mile radius of the county centroid (great circle distance)

- Select the closest airport as the first candidate airport

- Select the two airports with the highest enplanements as the second and third candidate airports

We impose a limitation on counties within regions designated as metropolitan statistical areas (MSA) by the Census Bureau. MSA's tend to have more airports within the MSA and nearby which tends to lead to inappropriate choices using the long trip rules above. An example, is the case of counties close to Washington D.C. for which Pittsburgh International Airport is a candidate airport (i.e., within 200 miles GCD) for long trips. This selection would be inappropriate, since Reagan National, Dulles International and Baltimore Washington airports are the more obvious choices. We impose an additional rule that travelers within MSA regions will not travel more than a hundred miles to find an airport, hence the candidate airport set for short trips is the choice set for all trips originating from within an MSA area. Various operational concepts have been proposed for SATS type trips, including private ownership, air-taxi and fractional ownership. Initially SATS was modeled operating as an ondemand air-taxi service. The baseline scenario models 3,416 airports in NAS where SATS services could be provided. The baseline SATS scenario assigns each county to one or more SATS airports. The SATS airport selection process is to designate a SATS airport as the closest to the county centroid (using the great circle distance).

\section{Generation of Flight Schedules}

\section{Description}

The Future Air Traffic Growth and Schedule Model was developed to project future traffic flow between airports in a system and of then scheduling the additional flights to reflect current passenger time-of-travel preferences. The methodology produces an unconstrained future schedule from a current (or baseline) schedule and the airport operations growth rates. Domestic and inter-continental US traffic and airports are included.

The model generates a future air traffic schedule based only on a current schedule and the predicted growth factors for each airport of interest for a future year. An implementation of the Fratar algorithm is used to create a future daily total number of flights between each origin and destination airport pair of the current schedule. The Fratar algorithm is a simple mathematical expression that is used to allocate future flights between origin and destination airports as a function of the product of the current flights between the origin and destination pairs and the growth factors for each airport.

\section{Fratar Algorithm Implementation}

The Mathematical formulation of the Fratar algorithm is: 


\section{$F_{i j}^{\prime}=\left(F_{i} \times G_{i}\right) \times \frac{\left(F_{i j} \times G_{i}\right)}{\sum_{n} F_{i n} \times G_{n}}$}

where

$\mathrm{F}_{i j}^{\prime}$ is the next estimate of flights from airport $i$ to airport $j$,

$\mathrm{F}_{i j}$ is the current estimate of flights from $i$ to $j$,

$\mathrm{F}_{i}$ is total flights from $i$,

$\mathrm{G}_{n}$ is the growth factor for airport $n$.

Setting the current estimate of flights to the current schedule value and the growth factors to the required growth factors initializes the algorithm. Subsequent iterations re-compute the growth factors as the ratio of the current estimate to the required number of flights. The Fratar growth factors therefore tend towards unity as the estimate converges towards the required number of flights. After each iteration the new estimate of flights from $i$ to $j$ and from $\mathrm{j}$ to $\mathrm{i}$ are equalized by taking the average.

The Growth Model implements the Fratar algorithm using whole numbers of flights. Not allowing fractional flights can lead to small discrepancies between the Frater computed values and the desired number of flights. For this reason a modification was made to allow the growth factors to be varied slightly from the Fratar computed values to give a closer convergence between the required number of flights and the Fratar computed values. Setting a flag in the input file enables this optional refinement.

\section{Future Schedule Generation}

The Frater algorithm is used to generate a daily total number of flights between each origin and destination pair. It is not used to generate an epoch to epoch total since the algorithm does not work well with small numbers of flights. It is therefore necessary to generate a new schedule by apportioning the future daily total flights to each time epoch in the day. This is done by maintaining the original schedule and then scheduling the additional flights to match the current cumulative departure schedule. The original schedule for the present study was the FAA Enhanced Traffic Management System ${ }^{22}$ (ETMS) data. The flights can then optionally be spaced in time according to the following rules:

- Schedule the additional flights evenly between the previous departure epoch and next departure epoch for the same destination where these flights exist.

- Schedule the additional flights evenly between the current time epoch and the next departure when only a later departure exists.

- Schedule the additional flights evenly between the current time epoch and the previous departure epoch when only an earlier departure exists.

- Schedule the additional flights at hourly intervals, subsequent to the current time for morning flights and prior to the current time for evening flights when only one flight exists in the current schedule.

This scheme causes some spreading of the existing arrival/departure patterns but in practice produces a plausible schedule that preserves much of the existing structure of the banks of arrivals and departures at hub airports. Not spacing the flights allocates new flights in the same departure/arrival epochs as current flights and may represent a less realistic scheduling policy. Since spacing the flights is optional, the user can decide which is the most appropriate scheduling policy for the study being undertaken. The Future Air Traffic Growth and Schedule Model was developed as an implementation of the Fratar algorithm to project future traffic flow between airports in a system and then scheduling the additional flights to reflect current passenger time-of-travel preferences. The methodology produces an unconstrained future schedule from a current (or baseline) schedule and the airport operations growth rates. Inter-continental US traffic and airports are included and the traffic is also grown with the Fratar methodology to account for their arrivals and departures to the continental US airports. 


\section{Results}

Predictions commonly concentrate on defining values of Revenue Passenger Miles (RPM), Operations or Enplanements to quantify the future demand for travel in the NAS. RPMs has been a very widely used parameter and is relatively easy to quantify from system traveler reporting. RPM sums up to a parameter that is easy to apply regression techniques to correlate RPMs with national socioeconomic variables and be able to apply techniques to project RPMs for a future in the NAS. However, the travelers enter the system at airports as enplanements and airlines provide service with aircraft through operations. Projecting RPMs even if accurate, provides limited information to future airspace planners and users as to the impacts of the airlines being able to provide flights with small delays to satisfy the traveling public demand and the FAA to provide sufficient capacity for the system to function efficiently. A major strength of tSAM compared to other models providing demand predictions for the NAS is that TSAM starts be predicting passenger demand for travel for every county in the continental US. Starting with demand at the person-trip level allows the prediction of enplanements at individual airports and then modeling the airline operations for various business models where the airlines can satisfy the available demand.

In this paper the various outputs of TSAM will be discussed as well as the sensitivities of the outputs to various input variables. This leads to another strength of the TSAM modeling system, it can be run numerous times for various hypothetical futures of input variables to allow system planners to have a range of various demand output variables and help develop a robust future system.

\section{Future Projections of Economic Indicators}

Before starting on the sensitivities of projections to the future variables it is noteworthy to compare the Consumer Price Index projections of TSAM compared to that used by the FAA for their future predictions. The FAA uses projections provided by the Office of Management and Budget (OMB). TSAM uses the Woods \& Poole

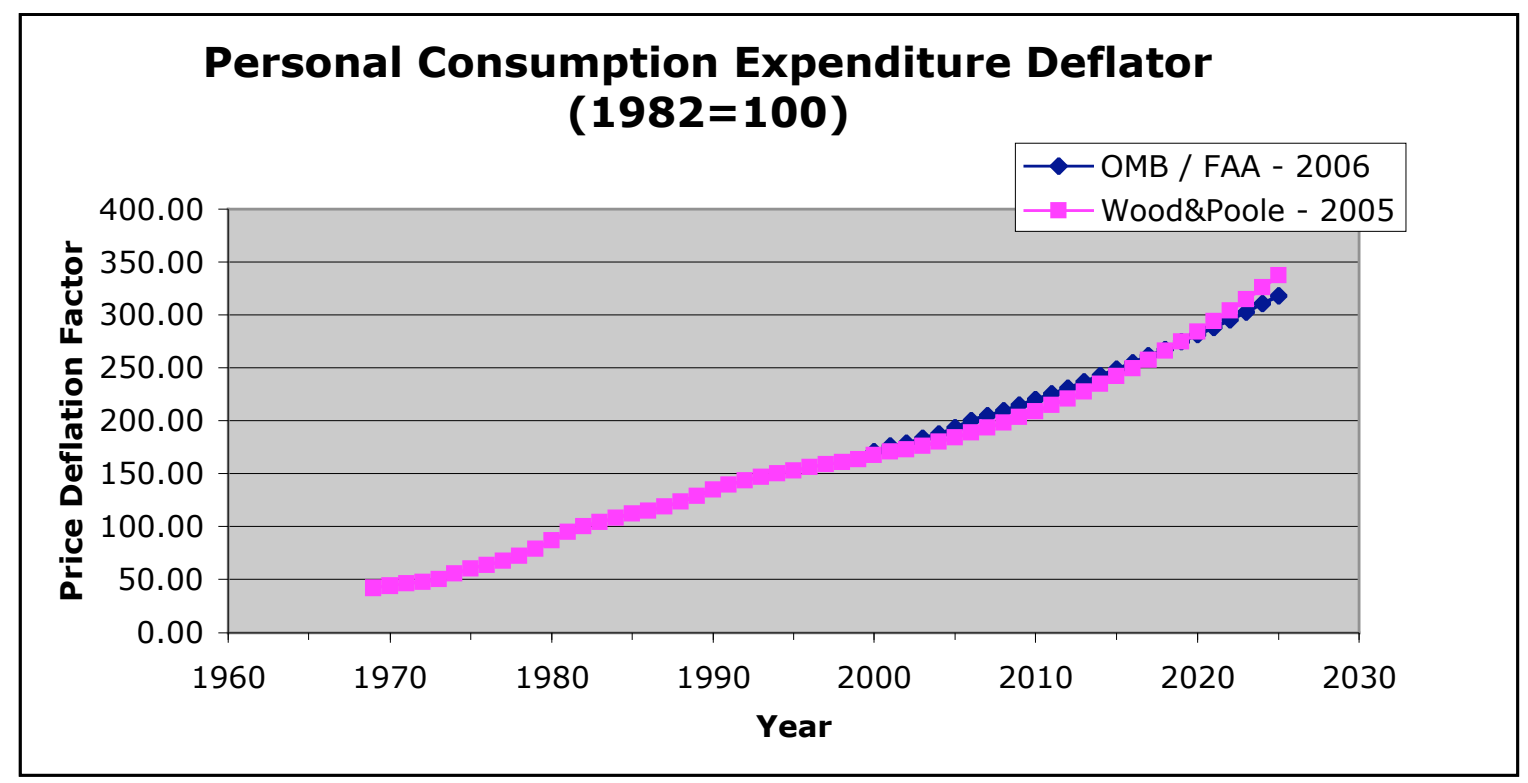

Figure 6. Comparison of Economic Indicators.

Complete Economic Database (CEED) that is projected by Woods \& Poole Economics. A comparison of the Woods \& Poole CPI with that used by the FAA is shown in figure 6. There is some small variation but generally good agreement in the projections out to 2025 . 


\section{Dependence of Commercial Airline Enplanements on Fare Yield}

Historical data indicates a very strong dependence on the fare yield reduction and the growth on

enplanements. This can be seen in the results in figure 7. From 1960 to the present day, the fare yield (in year 2000 $\$$ ) has reduced to less than $1 / 3$ of its value, from 35 cents/mile to a little over 10 cents/mile. In the same time frame, the enplanements have increased nearly 10 fold from 80 million to 800 million. This data includes both domestic

\section{Relationship of Historical Enplanements to Fare Yield Reductions}

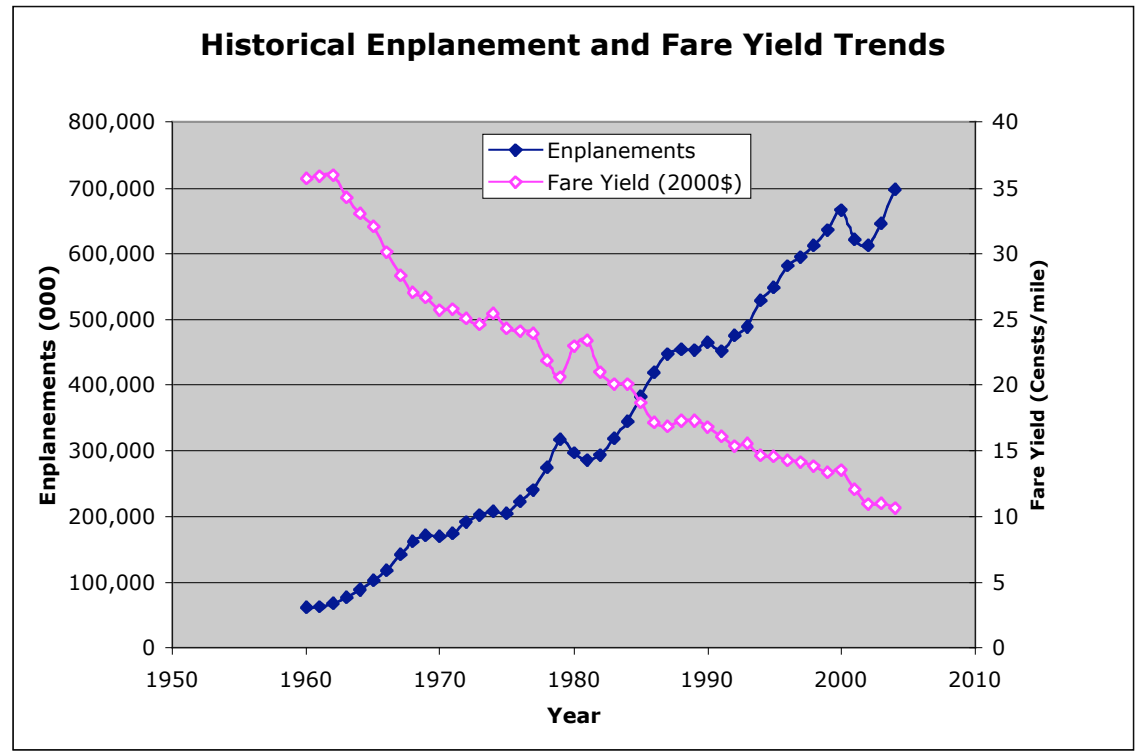

Figure 7. Enplanement and Fare Yield historical data.

and international enplanements. This trend has held true except for the 3 or 4 years right after deregulation of the airline industry in 1980 and also post 9/11 in 2001.

The dependence of enplanement growth on fare yield can be highlighted if we look at a hypothetical projection of enplanement growth as a negative factor of the change in fare yield. Figure 8 shows this dependence, where the growth in enplanements from 1960 to 2000 can be approximated by only 3 different regions of growth rates, $-3.7,-1.65$ and -2 . the slope of the fare yield. Years of slight positive fare yield grow had a significantly reduced growth rate. This closely coupled dependence of enplanement growth with fare yield decline is illustrated further by conducting a statistical analysis of the correlation. A correlation coefficient of 0.97 is achieved by conducting an analysis on the tow data series. Even though the authors by no means propose to use this as a method to project enplanements reliably into the future, the strong dependence of enplanements on fare yield growth is illustrated. 


\section{Enplanement Projections Based on Fare Yield Decrease}

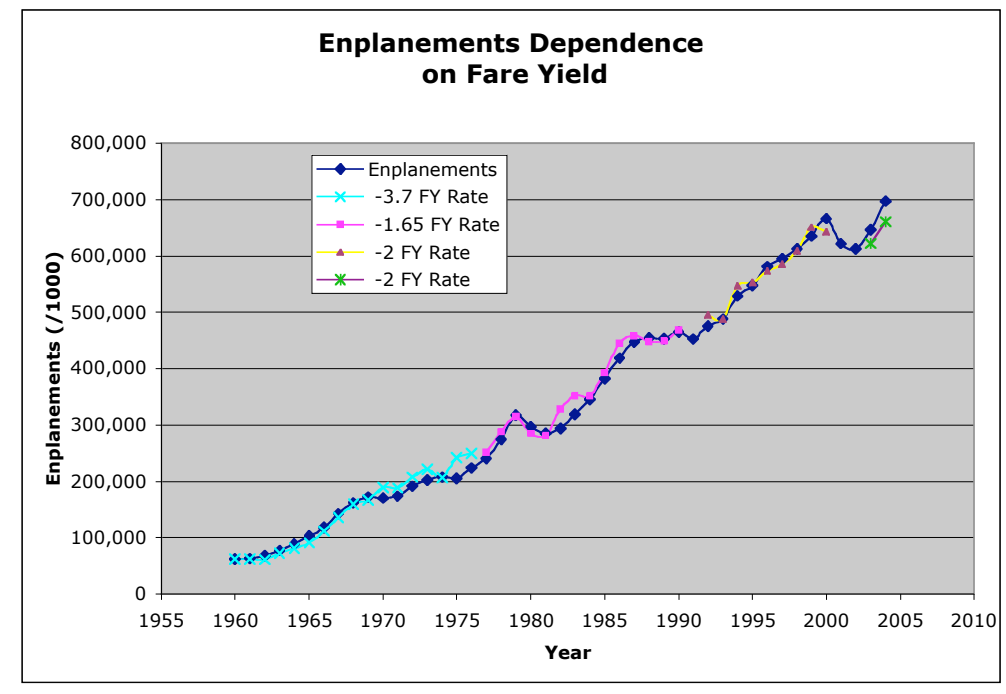

Figure 8. Approximating enplanement growth with Fare Yield slope.

\section{Overview Of Enplanement Demand Generation}

Future scheduled air carrier enplanements were projected using TSAM for a number of fare yield scenarios. The historical large growth in passenger traffic that the airline industry has experienced can be largely attributed to the fact that fare yields have dropped over 40 percent between 1980 and 2000 in real dollars (inflation adjusted dollars). Real fare yields have further dropped 30 percent from 2000 to January 2005, partially in response to overcapacity as a result of $9 / 11$, but largely due to the rapid growth of low cost carriers. The FAA 2005 Aerospace Forecast projects a continuation in the reduction of fare yields. The 2005 Aerospace Forecast projects 2014 fare yields to be 38 percent lower than 2000 averages, and if the rate of reduction is extrapolated beyond the 2016 range to 2025 the fare yield reduction is to 46 percent with respect to 2000 yields.

Three alternate fare yield scenarios have been examined. In one scenario the fare yield is reduced by 25 percent in real dollars with respect to 2000 averages for both 2014 and 2025. A 25 percent reduction from 2000 is

approximately the point where fare yields stand currently. The remaining two scenarios were examined in response to the cloudy outlook for the global petroleum supply, and price. If the price of oil continues to increase at a rate in excess of the overall cost-of-living, fare yields may not decline and could increase in real dollar terms if global petroleum demand greatly exceeds supply. The other passenger cost scenarios were a constant real 2000 dollar fare yield for 2014 and 2025 respectively, and 10 and 25 percent increases in real dollars for 2014 and 2025 respectively. These different fare yield scenarios and the historical reductions are shown in figure 9. 
Figures 10 and 11 show the predictions for growth in enplanements in the future. Figure 10 shows the enplanements ratioed to the fare yield reduction compared with the FY05 Aviation Forecasts and the TAF. Figure 11 shows the TSAM enplanement predictions to different fare yield scenarios compared to the projections based solely upon ratios to fare yield reduction rate. It can be seen that in 2025 , the difference in potential future fare

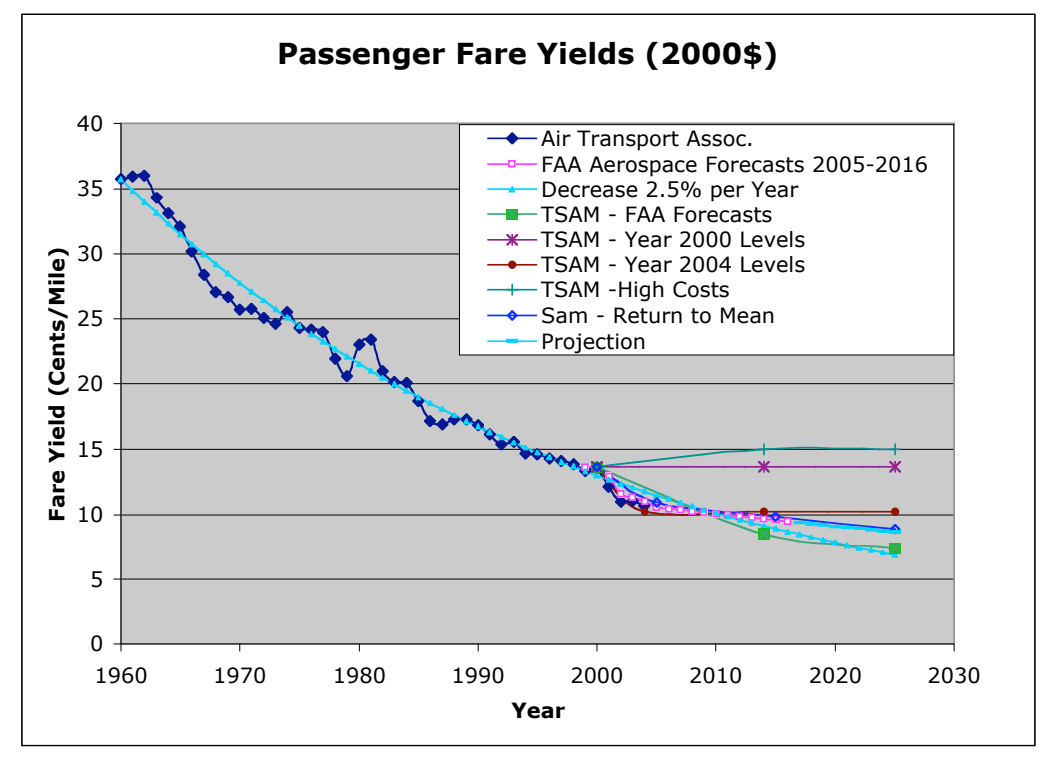

Figure 9. Fare Yield scenarios compared with historical values.

yields could produce changes in national enplanements between a total of 900 million and 1.3 billion, more than a $40 \%$ difference. This is a wide variation in possible demand and significantly different solutions for NGATS would be required when designing a system for either extreme.

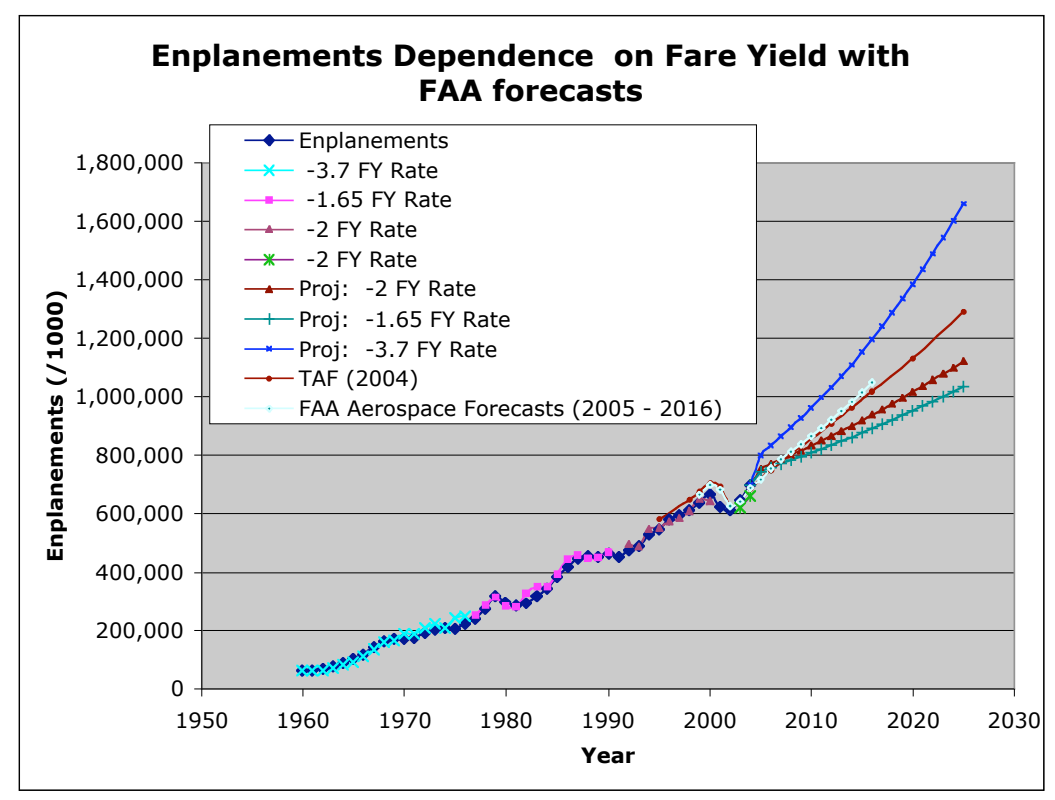

Figure 10. Projections of enplanements based upon the Fare Yield decline rate. 


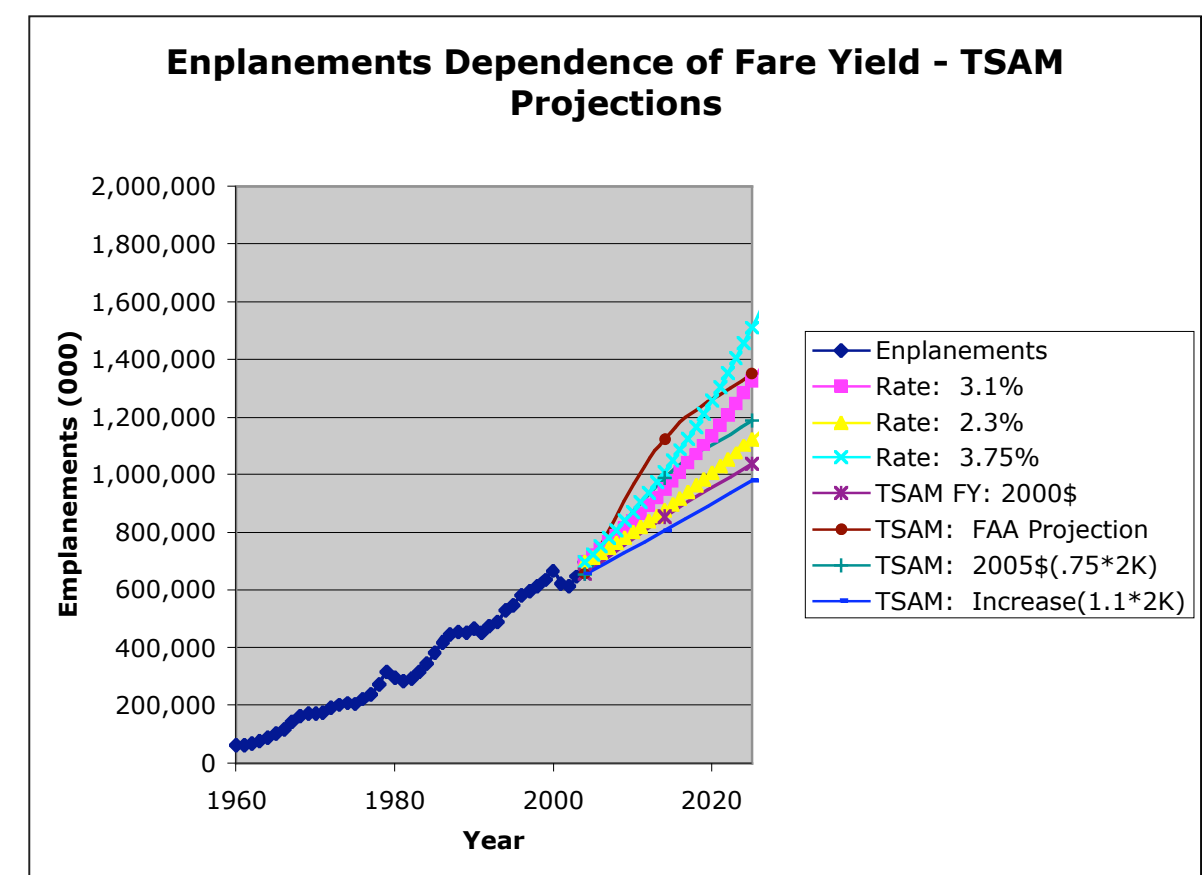

Figure 11. TSAM enplanement variations with various Fare Yield inputs. 


\section{TSAM Enplanement Projections Compared With FAA Aerospace Forecasts}

TSAM was run for three different fare yield scenarios for a range of years from 2000 to 2025 . Fare Yields are put input as a ratio to year 2000 dollars. TSAM uses constant year 2000 real dollars for all cost computations. A summary of the Fare Yield inputs is shown in Table I.

\begin{tabular}{|l|l|l|l|}
\cline { 2 - 4 } \multicolumn{1}{c|}{} & $\begin{array}{l}\text { FAA Fare Yield } \\
\text { Aerospace } \\
\text { Forecasts } \\
\text { 2006 }-\mathbf{2 0 1 7}\end{array}$ & $\begin{array}{l}\text { Return to } \\
\text { the Mean } \\
\text { Fare Yield } \\
\text { (eliminates 9/11 } \\
\text { discontinuity) }\end{array}$ & $\begin{array}{l}\text { Fare Yield } \\
\text { At Constant } \\
\text { Year 2000 \$ }\end{array}$ \\
\hline Year & \multicolumn{3}{|c|}{ Fare Yield } \\
\hline $\mathbf{2 0 0 0}$ & 1 & 1 & 1 \\
\hline $\mathbf{2 0 0 5}$ & 0.7119 & 0.9210 & 1 \\
\hline $\mathbf{2 0 1 4}$ & 0.6655 & 0.7800 & 1 \\
\hline $\mathbf{2 0 2 0}$ & 0.6298 & 0.7070 & 1 \\
\hline $\mathbf{2 0 2 5}$ & 0.5995 & 0.6500 & 1 \\
\hline
\end{tabular}

Table 3. TSAM input Fare Yield scenarios.

TSAM was run for the 3 different fare yield scenarios and for the years from 2000 to 2025 . The output enplanement results are shown in figure 12 compared with historical trends and the FAA Aerospace forecast enplanement projections. It can be seen that there is a wide variation in enplanement numbers, depending on the fare yield input. The huge reduction in air travel following $9 / 11$ is not captured in the TSAM model and projections continue in reasonable trends for the year 2000 for the various fare yields. The FAA enplanement growth follows a very similar trend to the historical enplanement growth trend, however the projections take into account the reductions imposed on the system as a result of $9 / 11$.

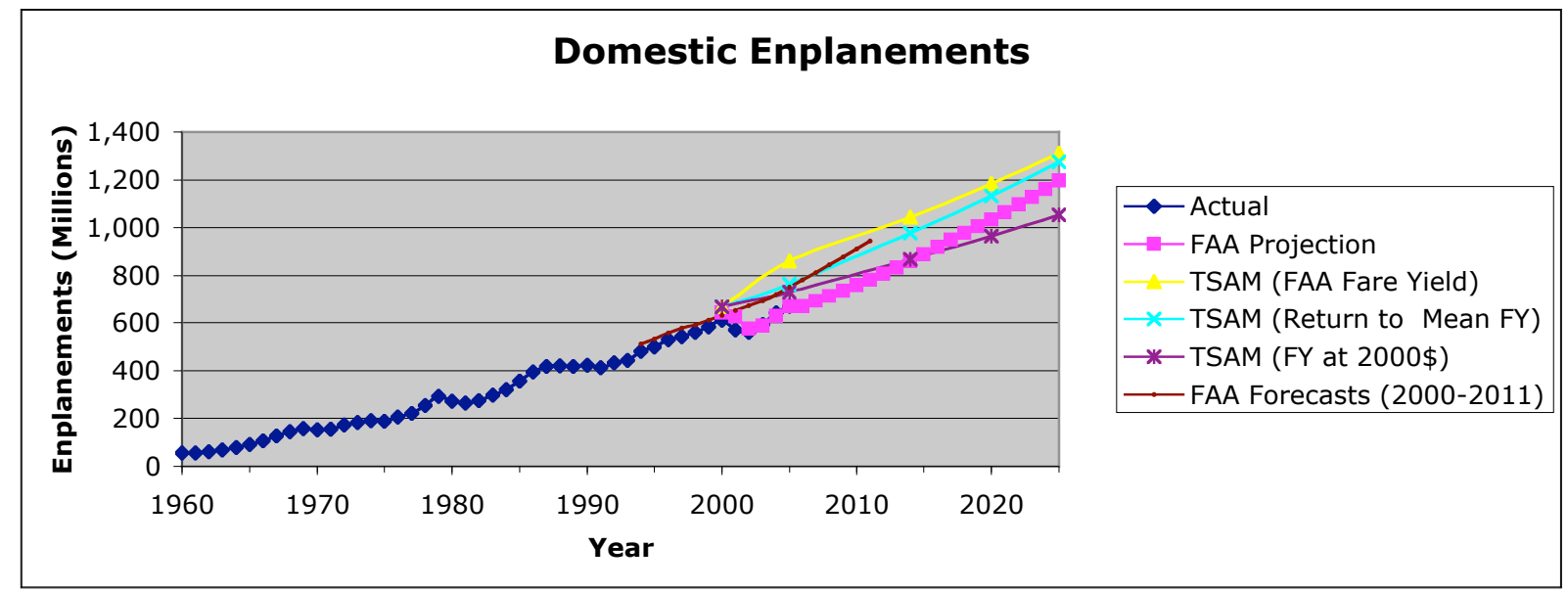

Figure 12. Domestic enplanements - historical, FAA 2006 Aerospace Forecasts and TSAM projections. 
A short history of the FAA Aerospace forecast projections of enplanements is shown in figure 13. The years shown are for forecasts from 2000-2011 to 2006-2017. The 2000-2011 forecasts are pre-9/11 and don't reflect the radical change to the system and the sharp reduction in enplanements that occurred. The general growth projections are very similar, with an offset for 2001. In general it appears as if the FAA projection s just assume an offset to the system with projection growth rates being the same into the future. We could conduct similar studies and projections with TSAM, just assuming a step reduction in the values as a result to the 2001 disruption. Figure 14 shows the TSAM projections plotted with the FAA aerospace forecasts in the years from 1995 to 2025 . The latest projections, 2006-2017 are included that have the offset of 2001 represented.. However the 2000-2011 forecast

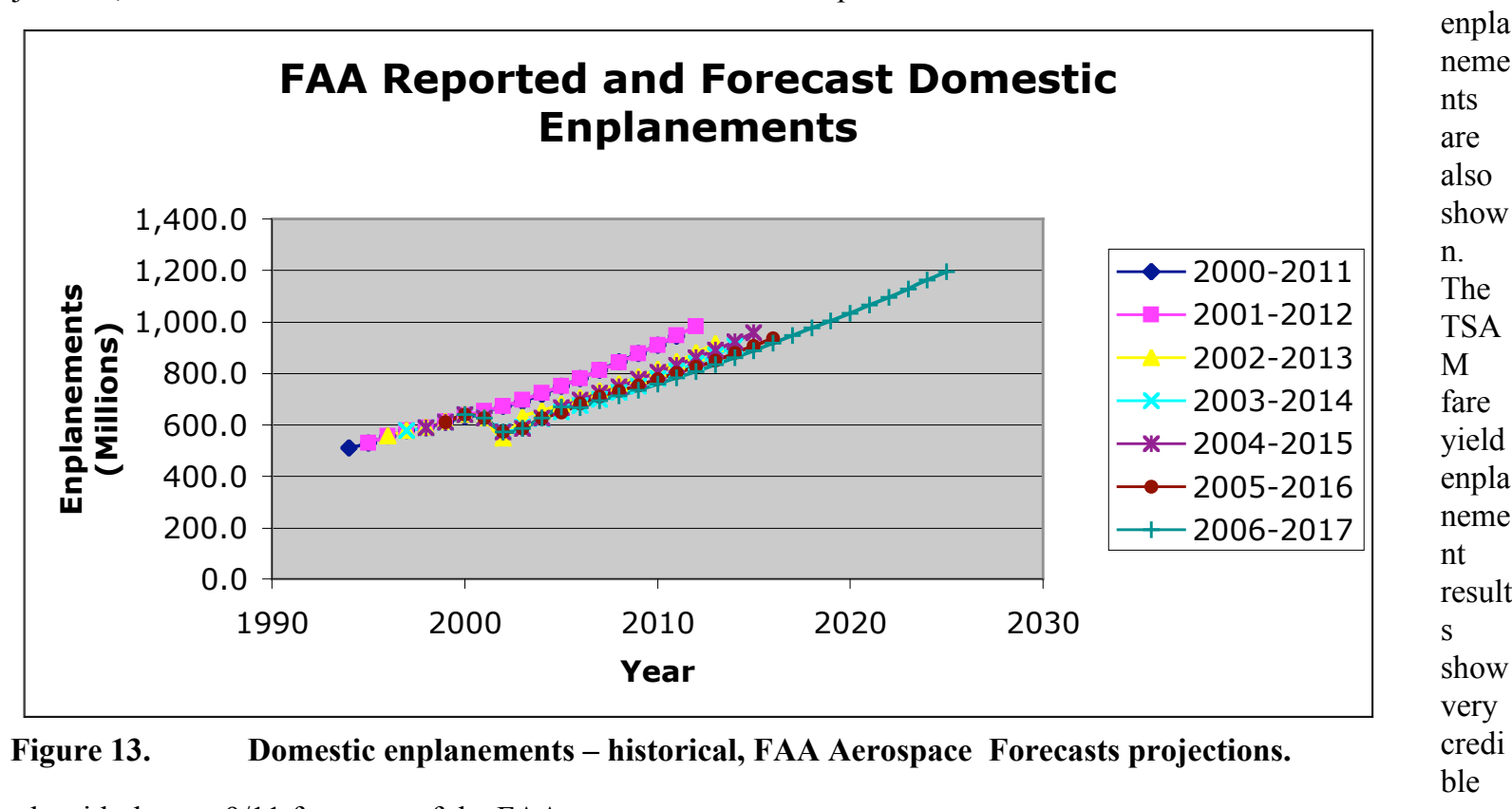

trends with the pre-9/11 forecasts of the FAA.

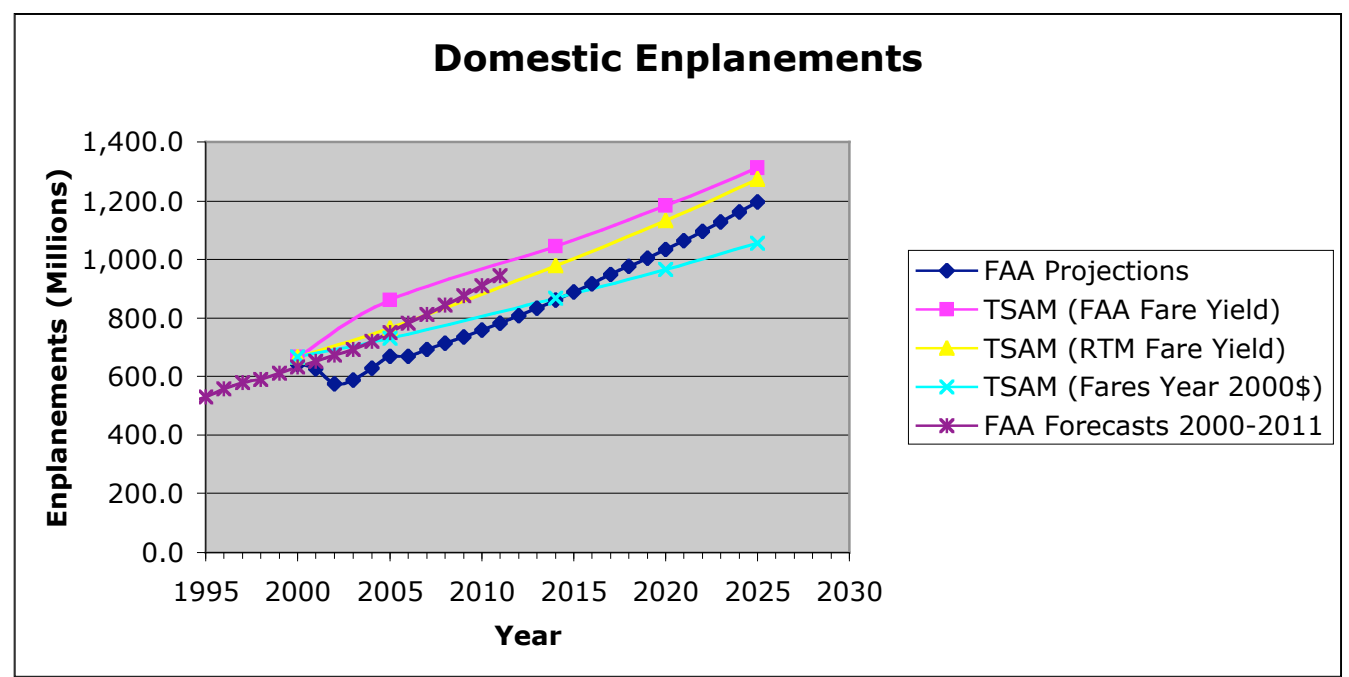

Figure 14. Domestic enplanement projections. 


\section{TSAM Revenue Passenger Mile Projections}

TSAM RPM projections were compared with those from the FAA Aerospace forecasts. First it is interesting to note the trends in average trip length which the FAA uses to convert enplanements to RPMs. The FAA projects RPMs at a national level into the future. Then it assumes (or projects) an average trip distance per enplanement. It divides the RPM projections by the average trip length to get the enplanement projections. A comparison of the computed TSAM average trip length compared with the FAA assumptions is shown in figure 15. It is interesting to note the very drastic differences in the trends. The FAA assumes that as the price of traveling goes down in real dollars, that travelers will travel farther. This relates to a constant travel budget philosophy.

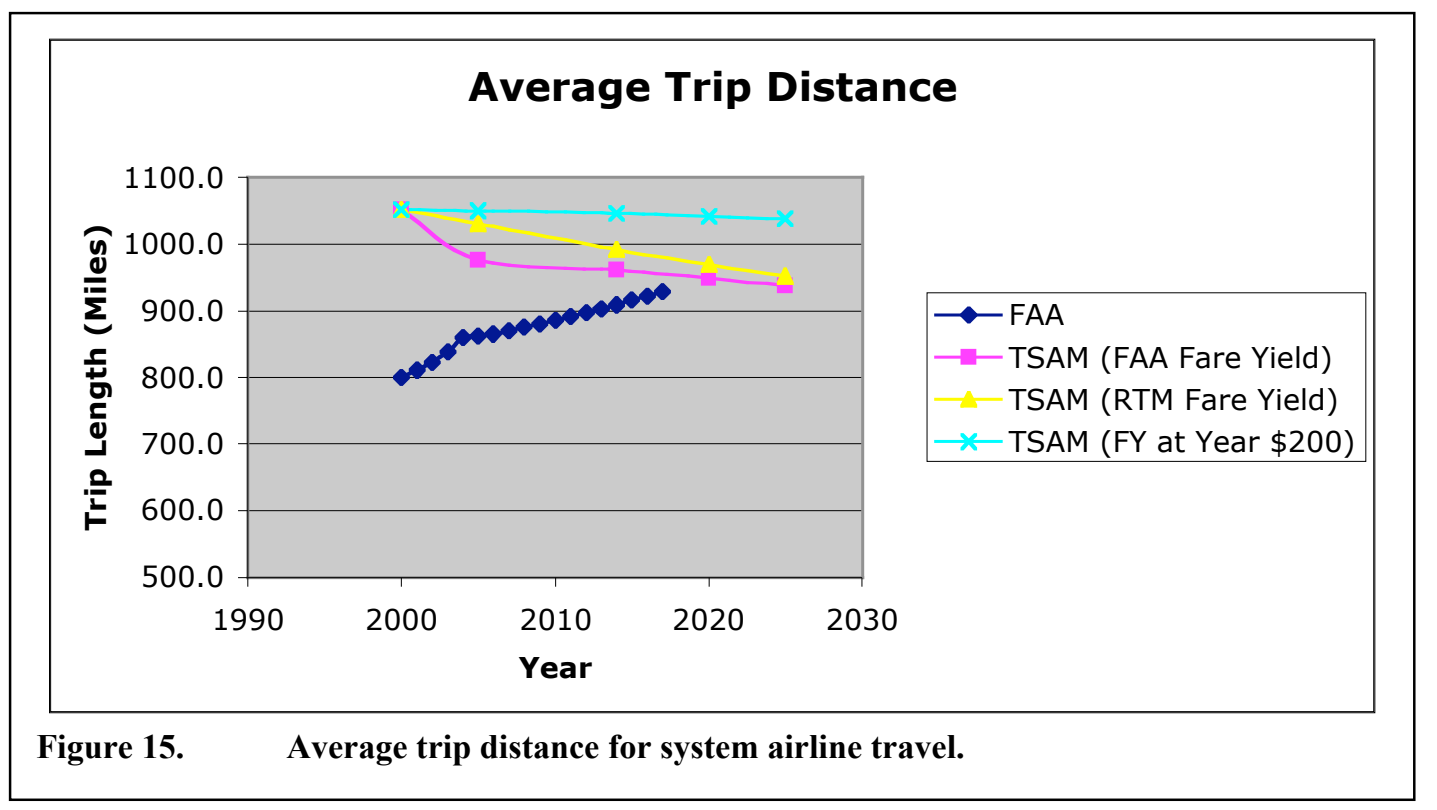

However, the continental US is only so large, and aircraft market costs are driven as much by competition as they are by cost per seat mile. The TSAM average trip length is a result of the computations predicting demand to take trips based upon cost and value of time. The trends out of TSAM show that as the fare yield is reduced, that shorter flights will have more value to the traveling public compared to automobile. Therefore they will take shorter trips. 


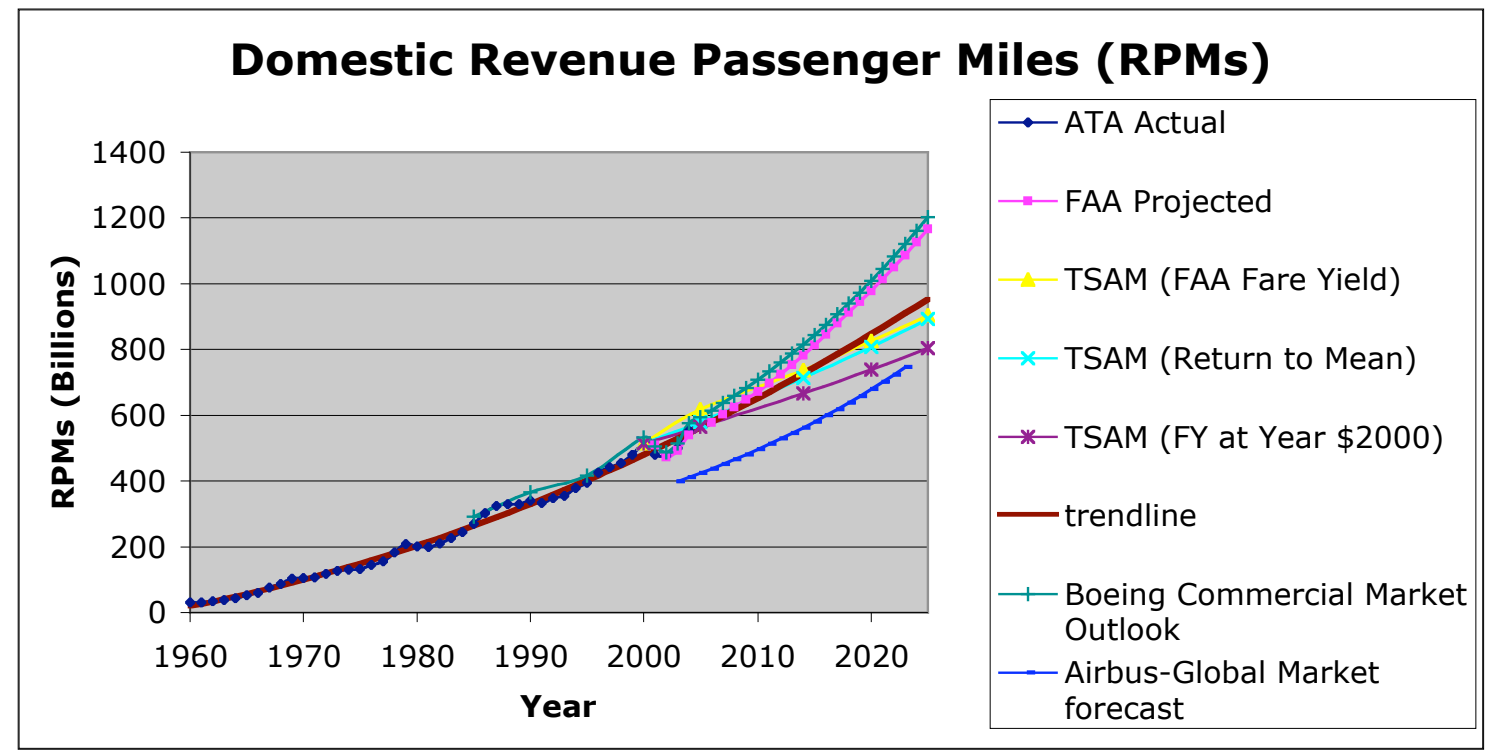

Figure 16. Domestic Revenue Passenger Miles Predictions.

Figure 16 shows the projections for national Revenue Passenger Miles (RPMs) compared with historical results. The FAA Aerospace Forecast projections are shown with those computed from TSAM. TSAM results are shown for the 3 fare yield scenarios indicated earlier. As expected if fares are projected to not reduce in the future, then the national RPM projections will decease. It can be seen that the slope of the FAA projections out to 2025 is significantly greater than the TSAM results. The TSAM projections are at least 200 billion RPMs less than the FAA projections of 2025. A trendline was generated through the historical data and extended into the future. An enlarged figure of the projections is shown in figure 17. It can be seen that the TSAM results with the FAA fare yield inputs is very close to the extrapolated trendline. It should be noted that the actual FAA projections extend to 2017, and then an extrapolation is made to 2025 from the average yearly increase of $3.6 \%$ per year given by the FAA in their forecasts.

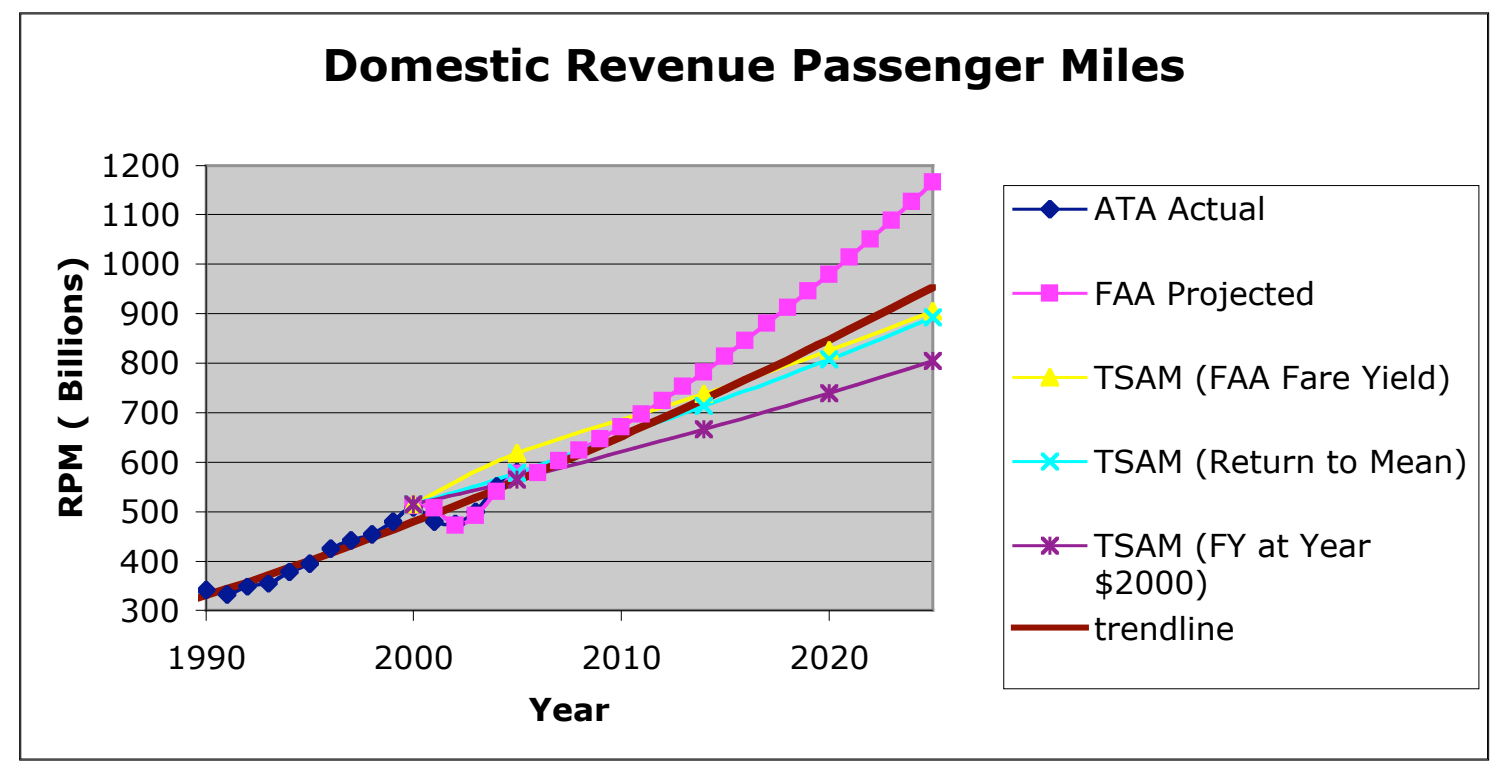

Figure 17. Domestic Revenue Passenger Miles Predictions. 
It is interesting to point out the different methods used by the FAA and TSAM to compute the RPMS in figures 16 and 17. The FAA projects RPMS at a national level based upon trends of air traffic growth and socioeconimic projections fo rth e country. TSAM computes the demand for long distance travel at the county level. Then a mode choice algorithm determined the percentage of those long distance county to county trips that will that will be taken by commercial airline. Finally the trips are distributed to commercial airports and airline routes. From the summation of the person trips multiplied by each airline route, the average trip distance and RPMs are computed. Even though the methodology is vastly different then the FAA projections, the projections results for Future RPMs is very credible based upon the trends of history.

\section{TSAM Airport Enplanement Growth}

Results have been shown for national measures of demand, enplanements and RPMs. However, TSAM computes the demand for air travel at the county level. This feature in a national model, allows the ability to be able to predict individual airport travel demand in enplanements. In theory, this is true but to get from county level demand for travel to enplaments demand takes a few additional algotithms and additional methodology to convert basic persontrip data to enplaenments, This is required because a commercial airport may serve multiple counties. Or there may be airports in close enough proximity that a county's demand for travel may go to multiple airports. Across the county both situations exist. Therefore TSAM has an airport model to try and account for these situations when there is not a one-to-one mapping of a county's demand to a single airport and vice versa. TSAM incorporates an airport choice model methodology (explained earlier), however at this time we are currently conducting efforts to increase the fidelity of this choice model. In addition, there is a significant amount of connecting traffic nationally at the hibs. The FAA documents between, 32 and 36 percent of the national enplanements are a result of connecting flights. The TSAM development team is currently working on a model to account for the prediction of connecting flight in the demand prediction. Acknowledging this current limitations, the predicted growth in enplanements at an airport predicted by TSAM can be compared with airport growth predictions from the FAA's Terminal Area Forecast (TAF). The results of this comparison are shown in figure 18.

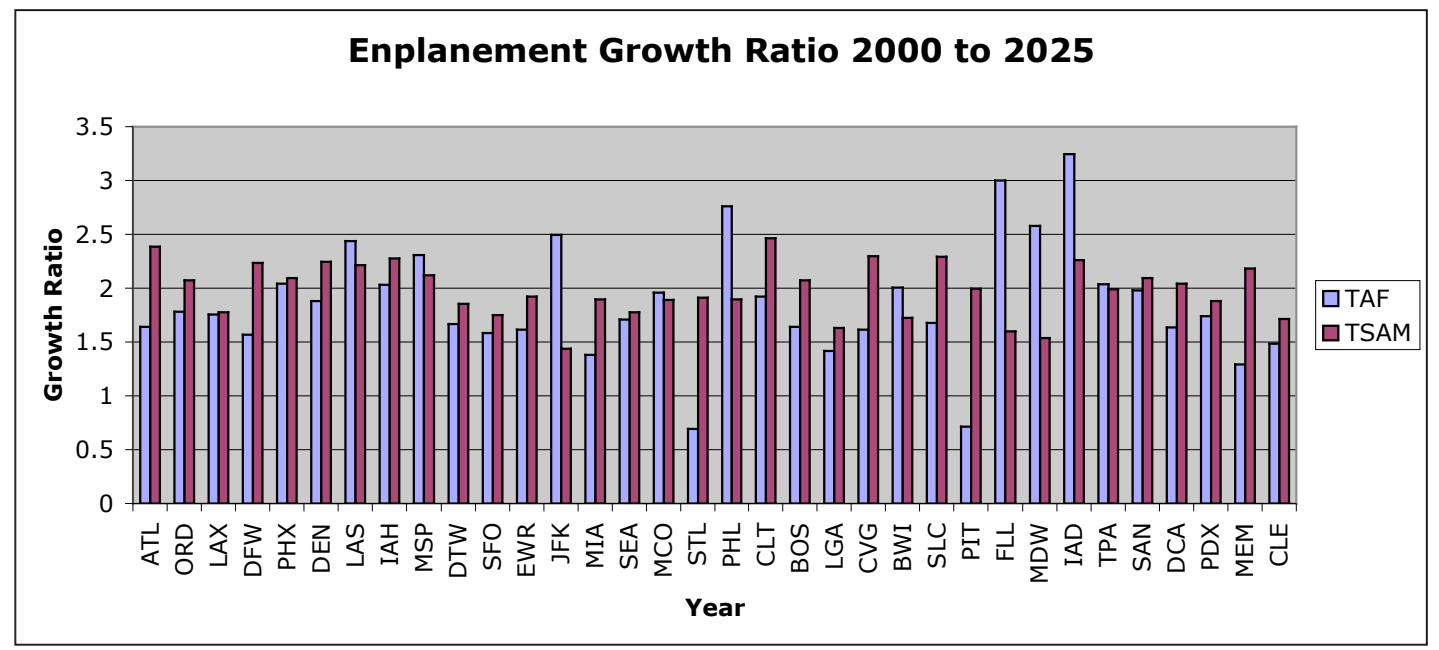

Figure 18. Predicted OEP airport enplanement growth ratio.

It can be seen that there are vastly different growth predictions for 5 OEP airports, where TSAM significantly underpredicts the growth compared to the TAF. These airports are Kennedy (JFK), Phildelphia (PHL), Dulles (IAH), Fort Lauderdale (FLL) and Midway (MDW). The year by year historical enplanement demand and FAA projections for these 5 OEP airports are shown in figure 19. Examining the historical enplanements and the FAA 2006 TAF projections it can be seen to some extent all of these airports saw a decrease in demand following the $9 / 11$ disruption in 2001. After bottoming out they each have seen a strong increase in demand. In general, this decrease after 2001 and the resulting strong increase after wards are not a result of demographics and are not currently captured by the TSAM model. Some of the strong growth can be explained by airline business decisions to put a major hub at a specific OEP airport. JFK's increase can be explained by Jet Blue initiating service there. 
IAD's strong growth and sharp decline around 2005 can be explained by the insurgence and resulting bankruptcy of Independence Air. It seems that the FAA projections are a result of the the continuing of this strong growth.

However especially in the case of IAD, there seems to be little historical evidence that this strong growth has ever occurred there. This helps shed some light on the huge discrepancies between these 5 OEP airports and the TSMA predicted growth, however we are still working on the individual airport prediction capability of TSAM. Included in the plot on figure 19 are the FAA TAF predictions form the 1997 TAF for IAD and JFK. They of course do not show the 2001 traffic disruption, nor the resulting strong growth that occurred afterward. These are included to help indicate the specific airline business decision concerning service played a role in the actual enplanement demand at these airports and not just the natural growth within the system.

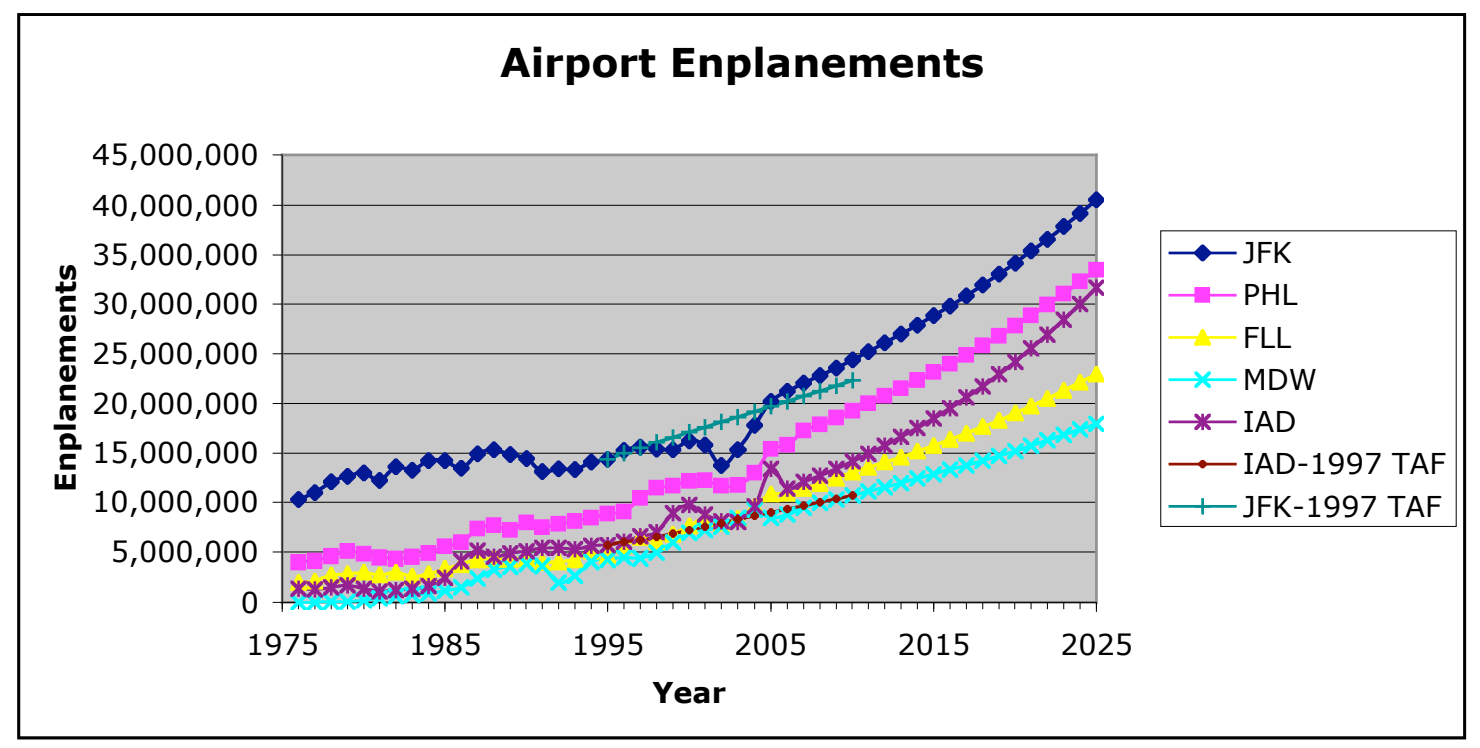

Figure 19. FAA histroicla and TAF enplanement projections for 5 OEP

\section{Future Scheduled Air Travel Scenarios}

TSAM was used to project the annual number of trip originations and destinations between 443 airports with commercial service (in year 2000) in the continental US. A round trip represents an enplanement at each airport in the to-and-from pair . Enplanements at an airport, are summed and the ratio of total annual enplanements to 2004 enplanements is computed to establish a growth factor for each airport. The computed growth factors are then used by a scheduler model which applies the Fratar algorithm to ETMS data to determine the number of flights needed to accommodate the growth.

Detailed data is available that includes projected enplanments for each airport with scheduled service, matrices of origin and destination enplanements between each of the airports, and flight schedules based on February 19, 2004 ETMS data grown via a Fratar algorithm. In addition, flight schedules were refined to include the introduction of larger aircraft and new direct flights. Larger aircraft were introduced on routes where demand required increased capacity and flight schedule frequencies were already sufficient to meet passenger's time of day preferences. New direct flights were introduced into the system when demand growth between direct city pairs was sufficient to support at least two flights a day in a regional jet size aircraft. 
Other traffic in the ETMS data set, such as cargo, unscheduled air taxi and GA was grown at the average overall growth rate (military traffic was removed from the original data set). The airport-to-airport enplanements matrix was examined for airport pairs with 25,000 or more annual enplanements between the airports and no direct service between the airports. Two direct flights per day of 50 passenger regional jets were introduced when the threshold of 25,000 annual enplanements was exceeded and the passengers and flights removed from being routed through the shortest connecting hub route. Larger aircraft were also introduced on routes with sufficiently high flight frequency, such that the economics of a larger aircraft are more important to the market than increasing schedule frequency. An algorithm derived from curves in the Airbus Global Market Forecast was used to substitute larger aircraft into service on appropriate routes.

A plot of the projected daily flights in the NAS is shown in figure 9 for the return to the mean fare yield reduction. The return to the mean fare yield projection is more conservative than the FAA forecasts for fare yield. This continues the trend in fare yield of pre $9 / 11$ to extend into the future.

\section{Conclusions}

The Transportation Systems Analysis Model (TSAM) is a valuable tool to predict the future demand for commercial airline travel. It is an extremely flexible model that can predict the national demand for travel starting with demographics and population at the county level. It will be a useful complimentary prediction to the FAA TAF forecasts. The FAA TAF forecasts are updated annually, and reflect the projections of a lengthy process that are the FAA's best projection of the future. The FAA results represent a specific set of assumptions in an industry and world economy that is changing rapidly and dramatically.. The TSAM model can be run with various assumptions and can be used for scenario planning for a variety of future states. For instance, the current rise in airline fuel prices and fare yields result in future scenarios that are not captured by a single set of assumptions. TSAM can be run to project the future demand for travel if these current economic affairs continue. TSAM can be a valuable planning tool for Airspace Capacity programs within the FAA and NASA, to help quantify the demand for travel given many possible future states. In this paper we have shown that TSAM can respond to variations in commercial airline fares and travel time. TSAM can show sensitivities to changes in national demographics and population.

We have illustrated a methodology for using the TSAM traveler demand outputs to commercial airline flights and projecting future loadings in the NAS. This methodology uses growth rate projections from baseline years to future years. The current TSAM model can predict origins and destinations of commercial airline trips. Future developments that will allow the prediction of the transfers at hubs will provide enhanced capability to predict the actual enplanements at all commercial airline airports, as well as be a useful tool to look at new future airline networks.

\section{References}

${ }^{1}$ Next Generation Air Transportation System Integrated Plan, http://jpdo.aero/integrated_plan.html

${ }^{2}$ FAA, Terminal Area Forecast Summary, http://www.apo.data.faa.gov/faatafall.HTM .

${ }^{3}$ FAA, Terminal Area Forecast, http://www.apo.data.faa.gov/faatafall.HTM .

${ }^{4}$ Boeing - Current Market Outlook, http://www.boeing.com/commercial/cmo .

${ }^{5}$ Airbus Global Market Forecast, 2005 to 2024 http://www.airbus.com/en/myairbus/global_market forcast.html .

${ }^{6}$ United States Census Data, http://www.census.gov/.

${ }^{7}$ ATS, American Travel Survey, Bureau of Transportation Statistics, http://www.bts.gov/publications/1995 american travel survey/index.html, 1995.

${ }^{8}$ Woods \& Poole Economics, http://www.woodsandpoole.com/, 2005.

${ }^{9}$ OAG, Official Airline Guide, http://www.oag.com/, 2004.

${ }^{10} \mathrm{DB} 1 \mathrm{~B}$, Bureau of Transportation Statistics (BTS), http://www.transtats.bts.gov/DatabaseInfo.asp?DB ID=125\&DB URL

${ }^{11}$ Microsoft MapPoint, http://www.microsoft.com/mappoint/products/2004/, 2004

${ }^{12}$ National Plan of Integrated Airport System (NPIAS), http://www.faa.gov/ .

${ }^{13}$ National Transportation Atlas Data, http://www.bts.gov/gis/ . 
${ }^{14}$ Eurocontrol Experimental Centre, Base of Aircraft Data (BADA) Aircraft Data: revision 3.5, EEC Note Number 09/03, Bretigny-Sur-Orge, France, July 2003.

${ }^{15}$ Bos, A.; "User Manual for the Base of Aircraft Data (BADA), Revision 2.6", Eurocontrol, EEC Note No.23/97, September 1997, http://www.eurocontrol.fr/projects/bada/

${ }^{16}$ Kanafani, A., Transportation Demand Analysis, McGraw-Hill, 1983 (pp. 105-114).

${ }^{17}$ Sheffi, Y.; Urban Transportation Networks: Equilibrium Analysis with Mathematical Methods. Prentice-Hall, Englewood Cliffs, NJ, 1985.

${ }^{18}$ Ortuzar, Juan de Dios and Willumsen, Luis G.; Modelling Transport, Wiley, 1994.

${ }^{19}$ Wieland, F; The Detailed Policy Assessment Tool (DPAT), Mitre Technical Report MTR 99W00000012, 1999.

${ }^{20}$ Long, Dou; Lee, David; Hees, Jing; Kostiuk, Peter; Upgrading LMINET- A Queuing Network Model of the National Airspace System, Logistics Management Institute, NS105S1, February 2002.

${ }^{21}$ Smith, J.; Dollyhigh, S.; Future Air Traffic Growth and Schedule Model NASA/CR-2004-213027, Jan. 2004

${ }^{22}$ Anon, Enhanced Traffic Management System (ETMS), Reference Manual, Version 7.6, Volpe National Transportation Systems Center, Report No. VNTSC-DTS56-TMS-004, May 2003, http://www2.faa.gov/tfmModernization/

${ }^{23}$ NASA Virtual Airspace Modeling and Simulation Project, http://vams.arc.nasa.gov/ .

${ }^{24}$ CTOD 7.39 - Airspace Concept Evaluation System (ACES) Build 3 Software User Manual, 30 September 2004, Contract Number NAS2-00015, Prepared by, Raytheon ATMSDI Team 